\title{
Analysis of a potential-vorticity streamer crossing the Alps during MAP IOP 15 on 6 November 1999
}

\author{
By KLAUS P. HOINKA ${ }^{1 *}$, EVELYNE RICHARD ${ }^{2}$, GORAZD POBERAJ ${ }^{1,4}$, REINHOLD BUSEN $^{1}$, \\ JEAN-LUC CACCIA ${ }^{3}$, ANDREAS FIX ${ }^{1}$ and HERMANN MANNSTEIN ${ }^{1}$ \\ ${ }^{1}$ Institut für Physik der Atmosphäre, DLR, Oberpfaffenhofen, Germany \\ ${ }^{2}$ Laboratoire d'Aérologie, CNRS and Université Paul Sabatier, Toulouse, France \\ ${ }^{3}$ Laboratoire de Sondages Electromagnétique de l'Environment Terrestre, CNRS/UTV, Toulon, France \\ ${ }^{4}$ Primorska Institute for Natural Sciences and Technology, Koper, Slovenia
}

\begin{abstract}
SUMMARY
In this study a potential-vorticity (PV) streamer which crossed the Alps during the Special Observing Period of the Mesoscale Alpine Programme (MAP) on 6 November 1999 is analysed. In situ aircraft data, wind-profiler data, model output data from the French non-hydrostatic mesoscale model (Meso-NH), and European Centre for Medium-Range Weather Forecasts (ECMWF) analyses are used to describe the structure and evolution of the streamer. In addition lower-stratospheric humidity which was remotely sensed by a Differential Absorption Lidar (DIAL) installed on board the aircraft is analysed. The comparison of measured and simulated lower-stratospheric humidity data show good agreement in structure and magnitude. The data analysis also reveals that waves are generated by the orography and transmitted into the lower stratosphere where they modify the streamer's PV structure. The impact of orography and diabatic processes on the streamer's evolution is simulated with Meso$\mathrm{NH}$ in a series of simulations. These simulations demonstrate that the separate effects of orography and diabatic processes are significant and comparable in magnitude, and that their combined influence leads to the formation of a PV cut-off. As a synergetic effect it is found that PV filaments are generated north of the Alpine barrier. The influence of orography and diabatic processes reduces the lower-stratospheric and upper-tropospheric PV by about $25 \%$ above the Alps, compared with the situation where neither effect is present.
\end{abstract}

Keywords: Cut-off low DIAL Mesoscale Alpine Programme Waves

\section{INTRODUCTION}

Narrow meridionally elongated troughs have been termed 'potential-vorticity streamers' because they are characterized by distinctive structures in the potential vorticity (PV) field (Appenzeller and Davies 1992). The synoptic climatology places such streamers preferably at the end of the Atlantic storm track. Typically north-eastward propagating surface cyclones reach maturity, decelerate, and begin to decay before landfall over northern Europe. During the same period the accompanying frontal systems swing south of the cyclones, weaken, and often almost stall over central Europe (Appenzeller et al. 1996).

What is the meteorological significance of these streamers? In the upper troposphere they induce a stratospheric-tropospheric mass exchange in the entire region, particularly in the area where the tropopause folds. In the folded zone, ozone-rich dry air of stratospheric origin is mixed by small-scale turbulent motion with ozone-poor humid air of tropospheric origin. There are strong winds and wind shear in the troposphere, in particular near the ground, which might be best described as an 'action at a distance'. Beneath the trough, the static stability is reduced and at the eastern flank of the streamer, convection and/or storms are produced. Browning and Golding (1995) reported a case with a tornado in England which occurred beneath the eastern flank of a PV streamer. In England about 50 tornados occur per year, some of them at the eastern side of PV streamers. If the streamer is advected it produces ascent and descent patterns which force and suppress convection. This convection can be enhanced by up

* Corresponding author: Institut für Physik der Atmosphäre, DLR, Postfach 1116, D-82230 Wessling, Germany. e-mail: Klaus.Hoinka@dlr.de 
to $50 \%$ by a tropopause fold as estimated by Griffiths et al. (2000). At the ground there is an enhanced flow around the trough impinging on the Alps. This flow is lifted by the Alps, generating precipitation and sometimes flooding. Because these streamers are considered to be precursors of events of severe precipitation on the southern slopes of the Alps, emphasis is put on forecasting the streamer's evolution.

With the onset of heavy precipitation there is a possible interaction between the upper-tropospheric PV anomaly and the orographically forced PV generation established by the sustained diabatic heating (Morgenstern and Davies 1999). This midtropospheric PV can induce a modification of the PV streamer and thereby favour the formation of a PV cut-off. At present it is not clear what role the Alpine orography plays in the break-up of the PV streamer into two pieces, a northern part and a cut-off or a Genoa cyclone to the south of the Alps. A necessary prerequisite for the generation of a Genoa cyclone is the low-level blocking of cold air at the nothern edge of the Alps. Numerical studies show that orography and diabatic heating can impact upon the streamer as it traverses the Alps (e.g. Morgenstern and Davies 1999). They showed that an incident streamer can help to instigate and sustain mid-tropospheric diabatically induced PV generation, which can in turn disrupt the streamer. Orography as well as convection generate waves which, in preferable conditions, are transmitted into the stratosphere. At present it is unclear what role these waves play in modifying or even disrupting a streamer.

One scientific aim of the Mesoscale Alpine Programme (MAP) Special Observing Period (SOP) (Bougeault et al. 2001) was to study the impact of upper-tropospheric potential-vorticity streamers on the generation of heavy precipitation resulting in Alpine flood events. During the MAP experiment (autumn 1999) a prominent potential-vorticity streamer occurred during Intensive Observing Period (IOP) 15. The aircraft Falcon of the Deutsches Zentrum für Luft- und Raumfahrt (DLR) made two flights on 6 to 7 November 1999. The idea was to capture the evolution of the streamer as it crossed the Alps. In this paper the analysis of the data which were collected within this streamer is presented. Special emphasis is placed on the lower-stratospheric humidity structure which was measured by means of the newly developed airborne Differential Absorption Lidar (DIAL). In addition, European Centre for Medium-Range Weather Forecasts (ECMWF) analysis data and wind-profiler data are used to complement the analysis. Because the measured and observed data represent only a limited part of the reality of the observed atmospheric system, it became necessary to use mesoscale numerical simulations to link all measured data in order to provide a clear picture of the fourdimensional situation of this event. The model used is the French non-hydrostatic mesoscale model Meso-NH.

The purpose of the paper is to describe the structure and evolution of the observed PV streamer as completely as possible by an integrated analysis of different datasets including data from a newly developed DIAL. This case appears to be a typical example of a PV streamer crossing the Alps which is disrupted above them by forming a PV cutoff. Therefore, a further aim is to study the separate and combined influence of waves forced by orography and convection upon the streamer's evolution using numerical simulations. Two secondary goals are: (a) to provide evidence that the mesoscale model Meso-NH is able to properly simulate upper-level features of mesoscale extent such as a PV streamer; and (b) to show that the newly developed DIAL is able to measure low water-vapour mixing ratios to a sufficiently accurate degree.

The paper is structured as follows: section 2 describes all data that are used; section 3 summarizes the synoptic environment; section 4 discusses the cross-sectional structure of the streamer; this is followed by a presentation of the humidity field 
encountered within the streamer. In section 6 the upper-tropospheric aerosol distribution is analysed; in section 7 lower-stratospheric waves are explored; and in section 8 the impact of orography and diabatic heating on the streamer's evolution is discussed.

\section{THE DATA}

The lower-stratospheric flight track of the aircraft on 6 November (1248 UTC to 1642 UTC; see Fig. 1) was designed to cross the potential-vorticity streamer twice in the zonal direction. The reason for the high altitude was to collect cross-sectional humidity data with the DIAL instrument, which was installed on board the aircraft working in a downward-looking mode. Besides the standard in-flight measurement system, a fast-response cryogenic frost-point hygrometer was installed to measure in situ water vapour. This instrument measures dew or frost points between $30{ }^{\circ} \mathrm{C}$ and $-90{ }^{\circ} \mathrm{C}$ with an uncertainty of $0.3{ }^{\circ} \mathrm{C}$ and a response time of 6 to $30 \mathrm{~s}$. For ozone measurements an ultraviolet-absorption photometer was operated on board the aircraft. Its accuracy is $5 \%$ or 3 ppbv, whichever value is larger. Seven dropsondes were released from the aircraft between 1319 UTC and 1518 UTC (dots in Fig. 1).

The airborne DIAL system was used to measure two-dimensional distributions of water vapour and atmospheric backscatter along the flight track below the aircraft. This system operates in the strong water-vapour absorption band around $940 \mathrm{~nm}$ and fulfills all spectral requirements to measure low water-vapour contents down to a few ppmv (Ehret et al. 1998, 1999). In order to increase both spatial resolution and accuracy of measured water-vapour fields in relation to previous campaigns, the average output power of the DIAL transmitter had to be increased by one order of magnitude using a novel $100 \mathrm{~Hz}$ pump laser. A detailed description of the newly developed DIAL deployed during MAP can be found in Poberaj et al. (2002). The horizontal (vertical) resolution of the retrieved humidity data is $20 \mathrm{~km}(500 \mathrm{~m})$. The estimated systematic measurement errors are about $5 \%$. The resolution of the backscatter ratio data is $100 \mathrm{~m}(30 \mathrm{~m})$ in the horizontal (vertical).

During the MAP SOP, a French very high frequency (VHF) radar was operated at Lonate close to Milan. This wind profiler provided vertical profiles of the three wind components from $0.5 \mathrm{~km}$ to more than $15 \mathrm{~km}$ at a time resolution of $15 \mathrm{~min}$ (Caccia et al. 2001). This instrument is also able to monitor the tropopause altitude defined as the first height above 6-7 km for which the vertical echo power stops decreasing with altitude, being enhanced by the strong stratospheric refractive-index gradient. The tropopause heights are determined at a vertical resolution of $375 \mathrm{~m}$ by considering hourly averaged profiles in order to avoid errors in the echo power estimation due to a too poor signalto-noise ratio in the radar echoes.

A dataset was provided by the T319/L60 version of the ECMWF model. Its spectral horizontal representation is comparable with a resolution of about $50 \mathrm{~km}$ in midlatitudes. The ECMWF data were linearly interpolated between 12 and 18 UTC on 6 November in order to get data for the time when the aircraft crossed the streamer's central core and the sondes were dropped. The dynamically defined tropopause is assigned to the vertical position where the potential vorticity first exceeds the threshold value of $3.5 \mathrm{PV}$ units $\left(1 \mathrm{PVU}=1.0 \times 10^{-6} \mathrm{~K} \mathrm{~kg}^{-1} \mathrm{~m}^{2} \mathrm{~s}^{-1}\right)$.

Numerical simulations were performed with the French model Meso-NH (Lafore et al. 1998). Two interactively nested domains were used with horizontal resolutions of 32 and $8 \mathrm{~km}$. The vertical grid contains 50 layers, with a spacing of $50 \mathrm{~m}$ at the lower boundary progressively stretched to $600 \mathrm{~m}$ at a height of $10 \mathrm{~km}$. The top boundary condition located at $20 \mathrm{~km}$ is a rigid horizontal lid topping an absorbing layer of $6 \mathrm{~km}$ 

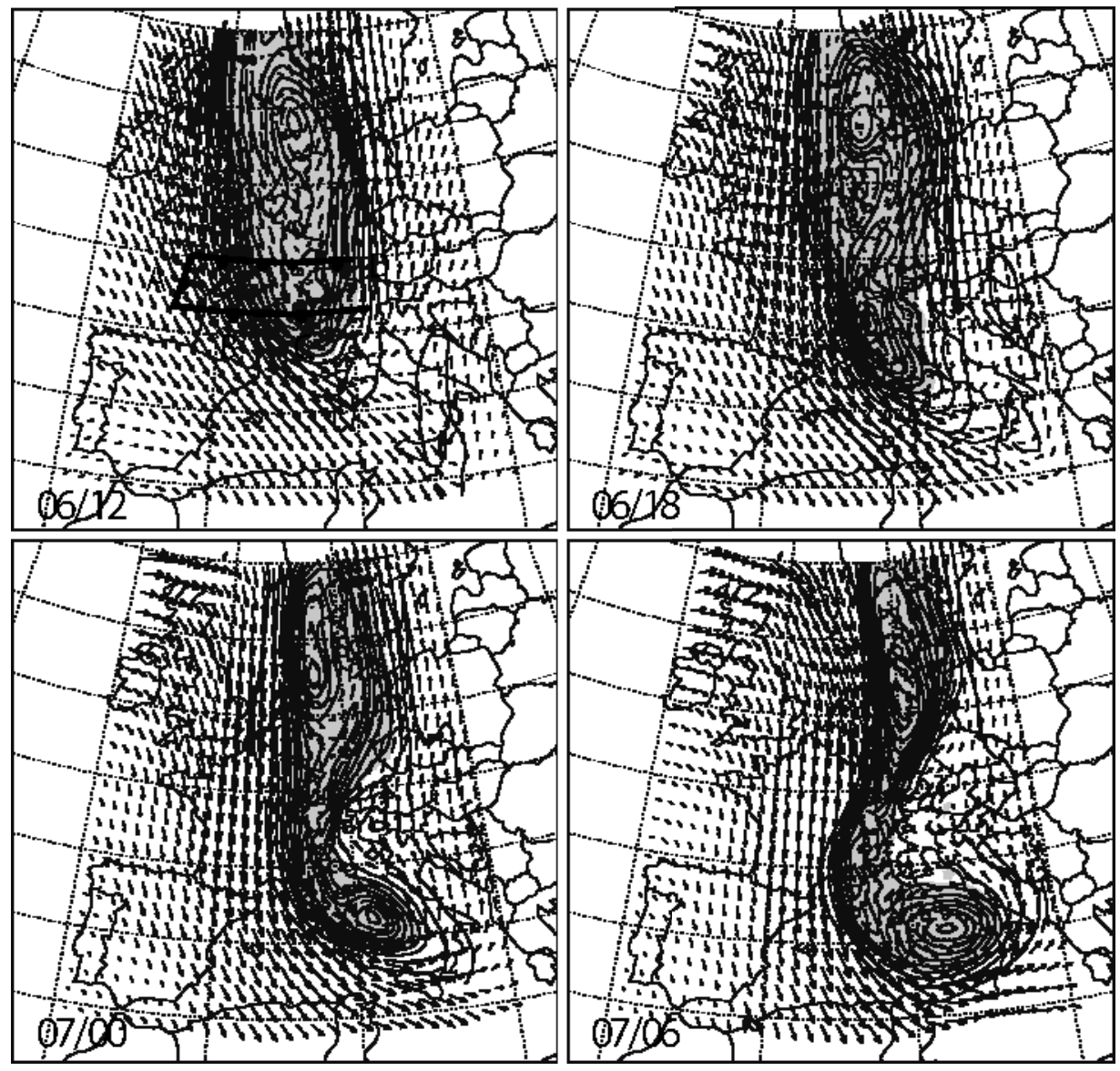

Figure 1. Potential vorticity (PV) (increment $1 \mathrm{PV}$ unit (PVU)) on the $320 \mathrm{~K}$ isentropic surface between 12 UTC 6 November 1999 (06/12) and 06 UTC of the following day (07/06) as derived from ECMWF operational analyses. The shaded areas indicate regions with potential vorticity larger than 3.5 PVU. The full line shows the baseline of the flight track where measurements were performed on 6 November. The dots mark the positions of the dropsondes; A, B, C and D are the locations of the vertical profilers given in Fig. 4.

TABLE 1. NUMERICAL EXPERIMENTS PERFORMED WITH THE MESO-NH MODEL

\begin{tabular}{cl}
\hline Experiment & \multicolumn{1}{c}{ Characteristics } \\
\hline $\mathrm{S}$ & Neither topography nor diabatic effects \\
$\mathrm{S}_{\mathrm{T}}$ & $\mathrm{S}$ including topography \\
$\mathrm{S}_{\mathrm{D}}$ & $\mathrm{S}$ including diabatic effects \\
$\mathrm{S}_{\mathrm{TD}}$ & $\mathrm{S}$ including both topography and diabatic effects \\
\hline
\end{tabular}

depth, designed to prevent reflection of upwardly propagating gravity waves. Initial and boundary conditions of the outermost model were obtained by interpolating ECMWF operational analyses available every six hours. The model was run with a full suite of physical parametrizations including a 1.5 -order turbulence closure parametrization. The simulation starts at 00 UTC on 6 November and ends on the following day at noon.

In order to study the impact of orography and cloud diabatic effects on the development of the streamer, four different simulations were performed (Table 1). Experiment 
$\mathrm{S}$ is designed to study the streamer's development above Europe independently of the Alpine orography and cloud diabatic effects, whereas experiment $\mathrm{S}_{\mathrm{TD}}$ is thought to provide the evolution closest to the observed one. Experiments $S_{T}$ and $S_{D}$ consider only topography and cloud diabatic processes, respectively. Thus, indications of orographic effects are provided by $\mathrm{S}_{\mathrm{TD}}-\mathrm{S}_{\mathrm{D}}$; of diabatic effects by $\mathrm{S}_{\mathrm{TD}}-\mathrm{S}_{\mathrm{T}}$; and of their combined influence by $\mathrm{S}_{\mathrm{TD}}-\mathrm{S}$. The synergetic influence of orography and diabatic effects is given by $\mathrm{S}+\mathrm{S}_{\mathrm{TD}}-\mathrm{S}_{\mathrm{T}}-\mathrm{S}_{\mathrm{D}}$. The quasi-pure influence of orography and diabatic effects can be determined by $S_{T}-S$ and $S_{D}-S$, respectively.

\section{THE SYNOPTIC ENVIRONMENT}

Gross features of the streamer which crossed Europe on 6/7 November 1999 are captured in the time sequence of the six-hourly potential-vorticity distribution on the $320 \mathrm{~K}$ isentropic surface (Fig. 1). As time progresses, the streamer elongates southwards and shifts slowly towards the east. At 00 UTC, 7 November the streamer's central part appears to be blocked by the Alps. In the following hours the zonal extension of the streamer narrows above the Alps and after 12 UTC the streamer breaks up into an elongated part north of the Alps, and a cut-off low south of the Alps. The latter moves rapidly with decreasing intensity towards the south-east and disappears on 9 November 1999.

In the Meteosat water-vapour images a tongue of dry air extending into the troposphere appears as a dark band (Fig. 2). Between 03 UTC of 6 and 7 November (Figs. 2(a), (b) and (c)) the water-vapour image shows the intrusion of dry stratospheric air reaching north-western France during the first day and progressing towards Sicily on the following day. At 15 UTC (Fig. 2(b)) when the aircraft measurements were made, the intrusion reached Sardinia. The central cyclone appears to be separately located to the east of the main intruding area. It is interesting to note that a narrow elongated spiral band of dry air connects the centre of the cyclone with the main intrusion region. The visible image (Fig. 2(d)) taken at the same time as that of the water vapour (Fig. 2(b)) shows the cyclonic spiralling of clouds above the low centre, and to the south-west of it the postfrontal clearing. The cloud-free area extends towards Sardinia while continuous clouds can be seen above the western Alps. Obviously there is a flow around the western Alps showing the typical cloud clearing during a strong mistral in the Rhône Valley. From the image time series it seems that the intrusion embraces the Alps from the west in a similar way to the upper-level PV anomaly shown in Fig. 1.

\section{THE CROSS-SECTIONAL STRUCTURE OF THE STREAMER}

On 6 November 1999 aircraft measurements were obtained around 1345 UTC above the northern cross-section $\left(48^{\circ} \mathrm{N}\right)$ and around 1515 UTC above the southern one $\left(45^{\circ} \mathrm{N}\right)$. Figure 3 shows the vertical wind velocity and PV along these cross-sections as simulated by Meso-NH (experiment $\mathrm{S}_{\mathrm{TD}}$, see Table 1). Also shown are the 100 and $300 \mathrm{ppmv}$ isolines of the water-vapour mixing ratio which can be used as approximate threshold values for separating tropospheric and stratospheric air. Additional hints for stratospheric air are areas with PV exceeding 3.5 PVU (shaded in Fig. 3). At $48^{\circ} \mathrm{N}$ a tropopause fold is apparent at the eastern flank of the streamer, dropping down to about $6 \mathrm{~km}$. The western flank of the streamer also exhibits a tropopause-fold-type structure but with weaker PV values. However, the 100 and 300 ppmv isolines show that dry stratospheric descent is deeper at the western edge than at its eastern counterpart. The western-most lowest point of the PV tongue is more to the west within the northern 


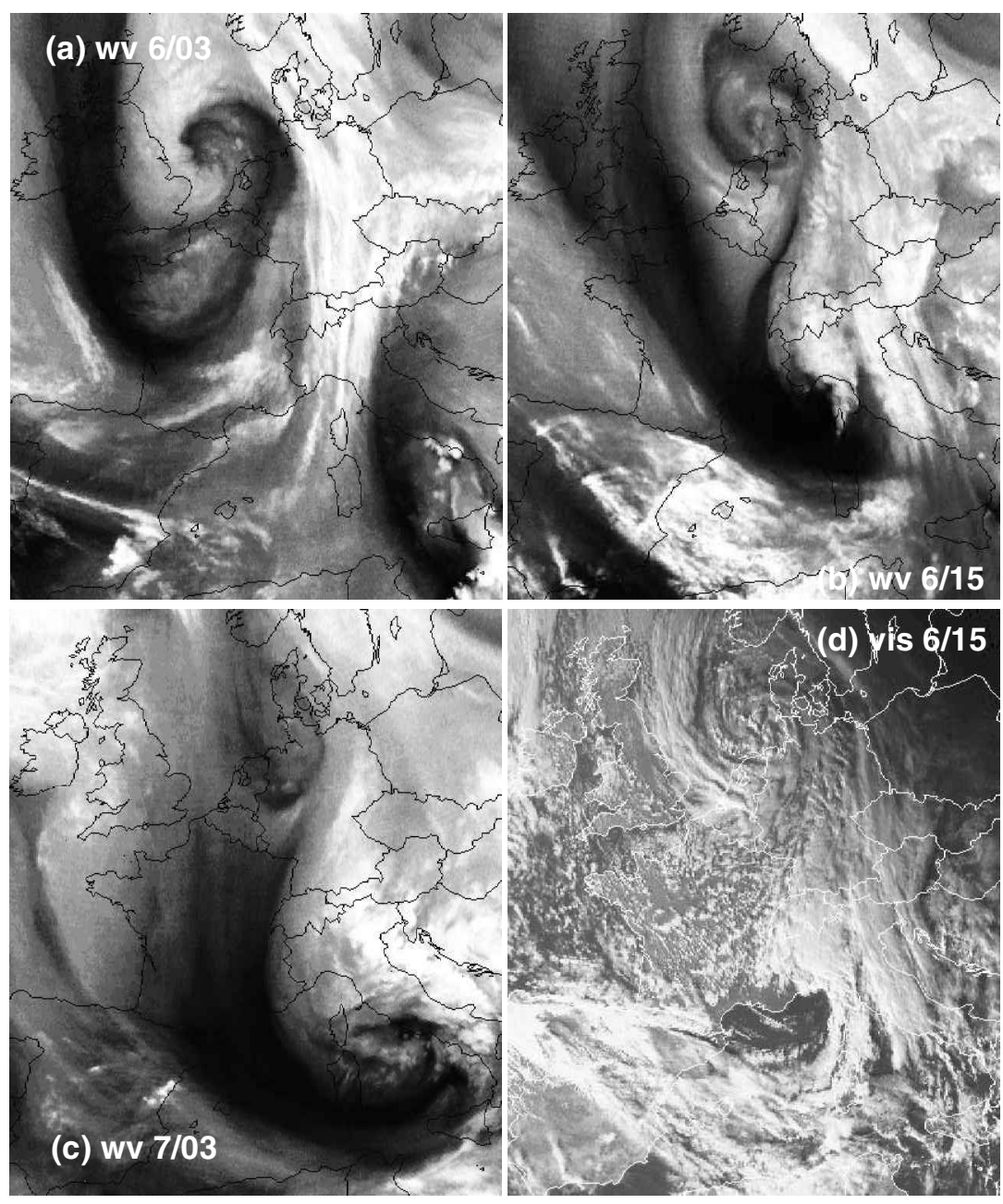

Figure 2. Meteosat images: (a) water vapour, 03 UTC 6 November 1999; (b) 15 UTC; (c) 03 UTC 7 November; and (d) visible, 15 UTC 6 November.

cross-section compared with the southern section because the streamer's axis bends towards the east at its southern edge.

Within the entire northern cross-section all vertical wind velocities are weak, whereas remarkable updraughts and downdraughts are simulated beneath the streamer's eastern flank within the southern cross-section. Updraughts of more than $50 \mathrm{~cm} \mathrm{~s}^{-1}$ occur at 1515 UTC to the east of the western Alps. At the same time a considerable descending motion of more than $60 \mathrm{~cm} \mathrm{~s}^{-1}$ appears close to the eastern Alpine slope. Within the core of the streamer in the lower stratosphere distinct up- and downward motion is simulated above the western Alps. We note that strong updraughts are generated in the same area where an increase in PV of more than 5 PVU is simulated. These updraughts produce considerable precipitation, which in turn enhances diabatic processes as a further generator of PV.

Figure 4 compares vertical profiles of water-vapour mixing ratio and potential vorticity taken at four positions on the streamer: (A) to the west of the streamer $\left(2.0^{\circ} \mathrm{W}\right)$; 


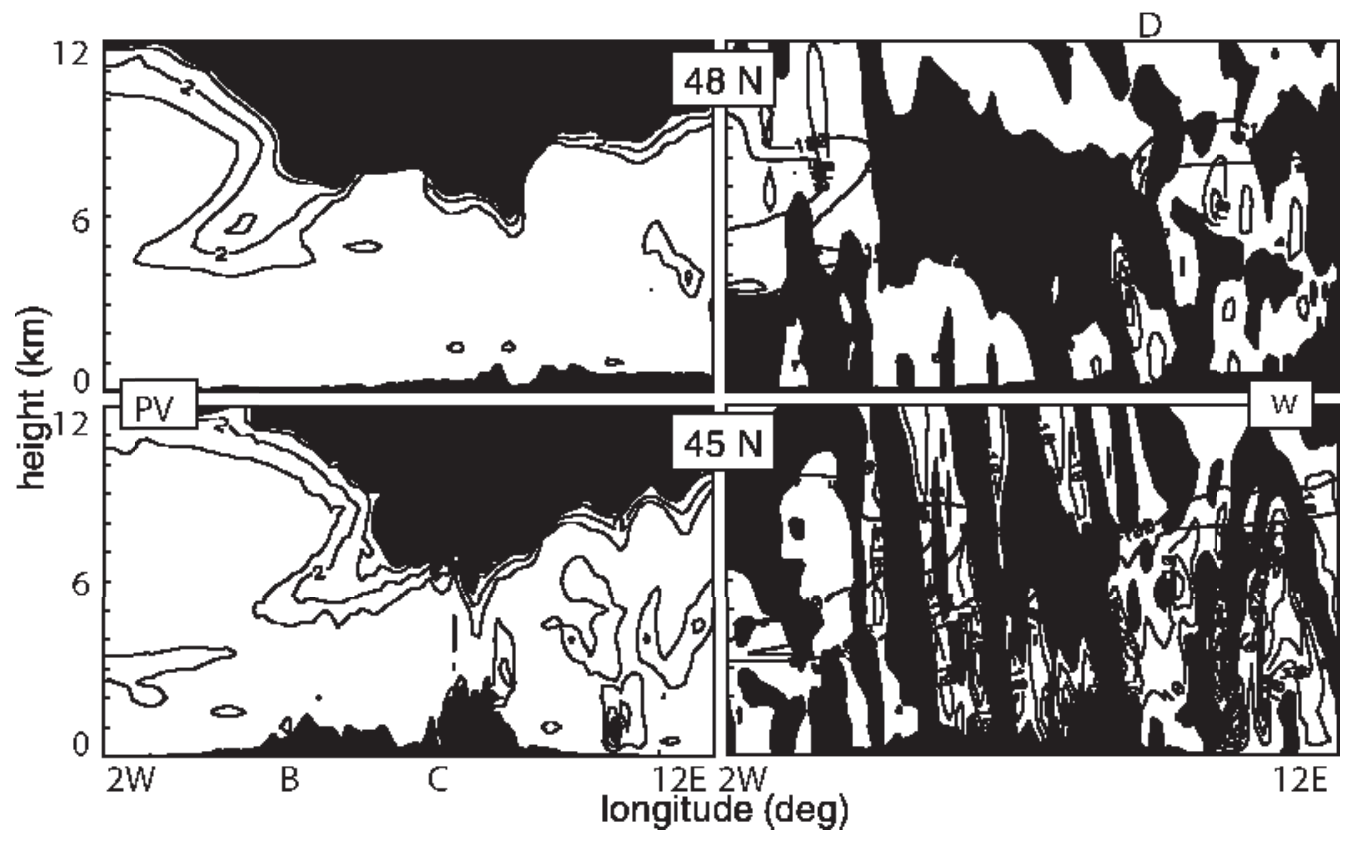

Figure 3. Cross-sections taken from Meso-NH simulations for 1345 UTC 6 November 1999 (top), and 1515 UTC (bottom). Potential vorticity (PV), increment $1 \mathrm{PV}$ unit (PVU); vertical velocity (w) increment $10 \mathrm{~cm} \mathrm{~s}^{-1}$; and the 100 and 300 ppmv isolines of mixing ratio. The shaded area indicates PV greater than 3.5 PVU and negative vertical velocity. The locations of vertical profiles as given in Figs. 1 and 4 are indicated by B, C and D.

(B) at its western flank $\left(1.8^{\circ} \mathrm{E}\right)$; (C) directly within it $\left(4.5^{\circ} \mathrm{E}\right)$; and (D) at its eastern flank $\left(7.1^{\circ} \mathrm{E}\right)$. All available data are displayed: ECMWF analysis, mesoscale numerical simulations, dropsondes, and DIAL. The profile data derived from ECMWF and MesoNH simulations were taken by assuming a hypothetical flight through the respective three-dimensional fields at the various drop times.

In the tropopause region (3.5 PVU), the PV exhibits the strongest gradient at the streamer's eastern flank (D), whereas at its centre (C) gradients of similar magnitude are located beneath and above the tropopause. At the western flank (B) a weak increase can be seen at a height of $5 \mathrm{~km}$ indicating the descending tongue of stratospheric air. The $\mathrm{PV}$ is comparable for the ECMWF analysis and the Meso-NH numerical simulation. Mixing-ratio profiles at the western location (A) and at the western flank (B), clearly show the increase in mixing ratio up to $200 \mathrm{ppmv}$ as soon as the dropsonde falls through the relatively humid part of tropospheric air between the stratosphere above and the tropopause fold beneath. A similar but weaker increase in mixing ratio is evident in the ECMWF analysis and the simulation data, but at lower levels. In the streamer's centre (C) all data show the expected increase in mixing ratio at around $5 \mathrm{~km}$ altitude while passing the tropopause from above. At the eastern flank (D) ECMWF and Meso-NH data show a smooth decrease with height when crossing the tropopause. However, the dropsonde exhibits a shallow layer (about $1.5 \mathrm{~km}$ deep) centred at $6.5 \mathrm{~km}$ altitude where the mixing ratio decreases strongly. This suggests that the dropsonde was able to record the relatively fine-scale shallow tongue of stratospheric air which bent downwards towards the east beneath the streamer's eastern flank. The corresponding PV structure at the northern cross-section around 1345 UTC seems to corroborate this or at least does not exclude this possibility. 


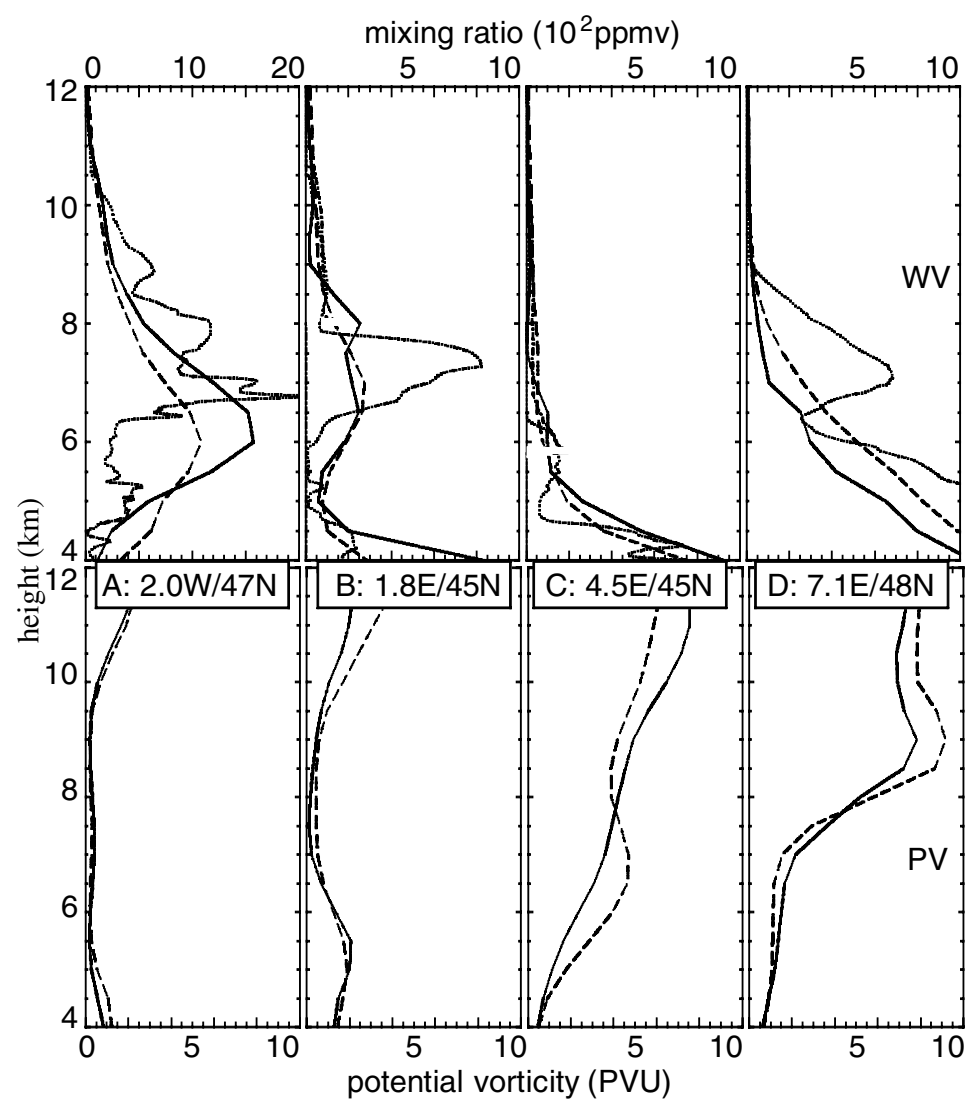

Figure 4. Vertical profiles of water-vapour mixing ratio (WV) and potential vorticity (PV) on 6 November 1999 along four positions crossing the streamer: interpolated ECMWF analysis (dashed lines); Meso-NH (full); dropsondes (dotted); and Differential Absorption Lidar (DIAL) (dashed-dotted, only for B and C and values below $100 \mathrm{ppmv}$ ). Note that the mixing-ratio scale for profile $\mathrm{A}$ is different to that for the other profiles. The locations of the profiles are given in Fig. 1.

The aircraft crossed the streamer within the stratosphere and the in situ instruments measured humidity and ozone along the flight track. In Fig. 5 the data series are given along the northern track at $48^{\circ} \mathrm{N}$ and its southern counterpart at $45^{\circ} \mathrm{N}$. The aircraft stayed within the stratosphere during the entire flight. Along both flight tracks there is an increase from east to west in water-vapour mixing ratio from about 8 to $20 \mathrm{ppmv}$ at constant height. This is due to the fact that the stratosphere is more humid above the western edge of the streamer than above the eastern one, which can be seen clearly in Fig. 6.

The ozone data show that the stratospheric ozone concentration at the eastern and western edge of the streamer was between 50 and 100 ppbv. However, above the streamer's core there is an increase up to $200 \mathrm{ppbv}$ along the northern flight track and to $150 \mathrm{ppbv}$ along the southern one. This indicates that there was ozone-rich stratospheric air probably originating from higher altitudes. A similar and corresponding decrease in the humidity is not observed because there is no significant lower-stratospheric change in water-vapour mixing ratio with increasing altitude. This is unlike the vertical profile of ozone where ozone increases strongly with increasing height within the stratosphere. It is interesting to note that the southern ozone data series shows lower ozone values 


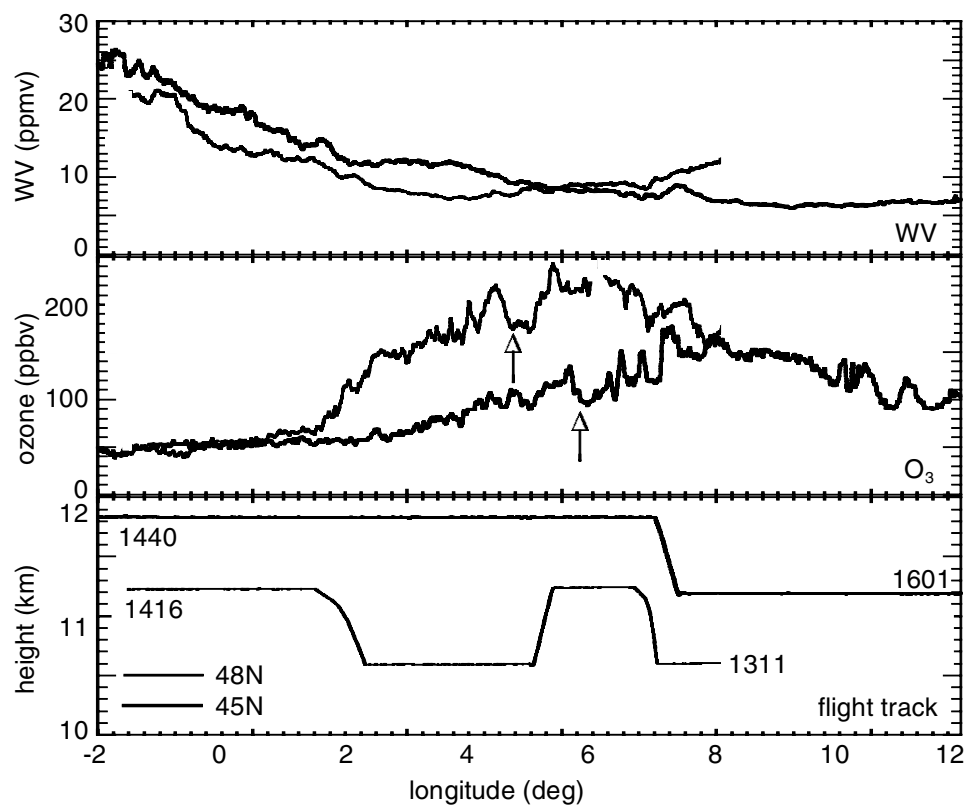

Figure 5. Mixing ratio of water vapour (WV) and ozone $\left(\mathrm{O}_{3}\right)$ as measured in situ by the aircraft along stratospheric flight tracks on 6 November 1999. The thin (bold) line designates the data along the northern (southern) track at $48^{\circ} \mathrm{N}\left(45^{\circ} \mathrm{N}\right)$. The time appearing at both ends of the flight tracks is given in UTC. The arrows are explained in the text.

than the northern one, although the mean altitude of the southern flight track is higher (about $11.5 \mathrm{~km}$ ) than the northern flight track (less than $11 \mathrm{~km}$ ). However, this gradient seems to vanish above the western and eastern edges of the streamer, whereas it is large above the streamer's core. At its southern location the core is slightly shifted towards the east by about two degrees of longitude because the streamer is not oriented completely meridionally.

The northward increase in the mean ozone values above the streamer's core is about $50 \mathrm{ppbv}$ across three degrees of latitude. Statistics of Total Ozone Mapping Spectrometer (TOMS) data show a similar pattern in the total ozone column (e.g. London and Oltmans 1979) with the strongest increase of about 20 Dobson units per 10 degrees during spring, whereas in autumn the gradient vanishes. This suggests that on 6 November 1999 there was a particularly strong meridional gradient in ozone within the lower stratosphere above the streamer's core. The Meteosat image indicates that along the northern cross-section the streamer's core lies to the west of $6^{\circ} \mathrm{E}$, while a narrow limited intrusion is situated east of $6^{\circ} \mathrm{E}$. In both ozone series there is a noticeable decrease in ozone of about $40 \mathrm{ppbv}$ at the same location where both branches of the intrusion are separated (see arrows in Fig. 5). Again the water-vapour mixing-ratio data do not show a similar signal.

\section{HUMIDITY WITHIN THE STREAMER}

This section discusses the upper- and lower-stratospheric humidity structures of the southern cross-section as observed and simulated on 6 November 1999. It repeats to a certain extent the analysis of an earlier event presented by Ehret et al. (1999). In this 
(a)

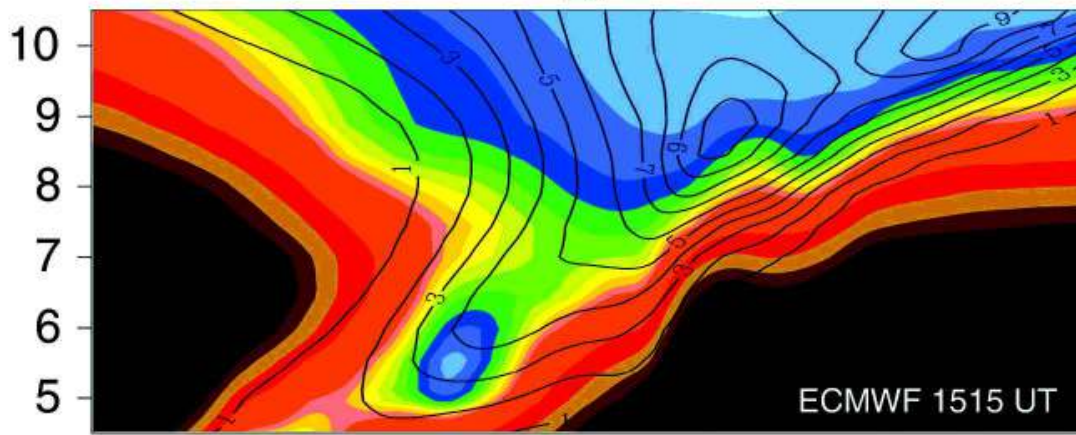

(b)

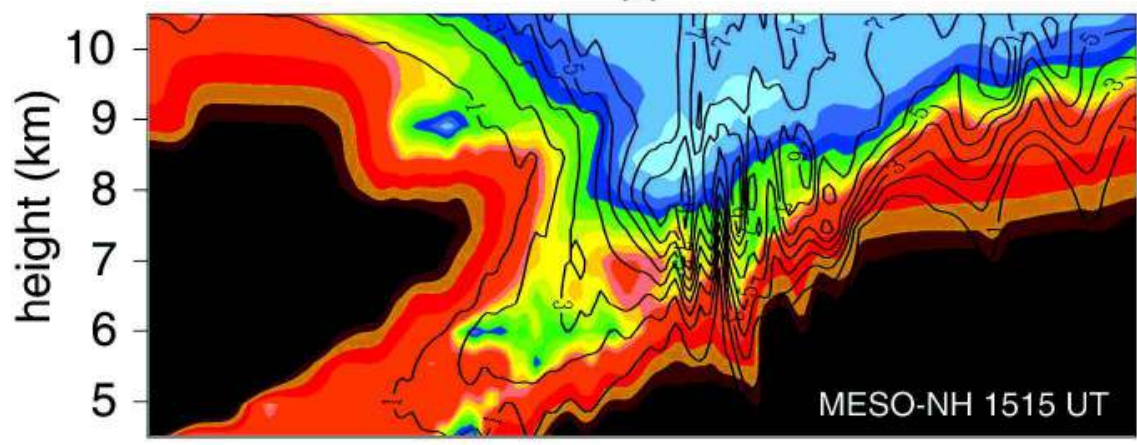

(c)

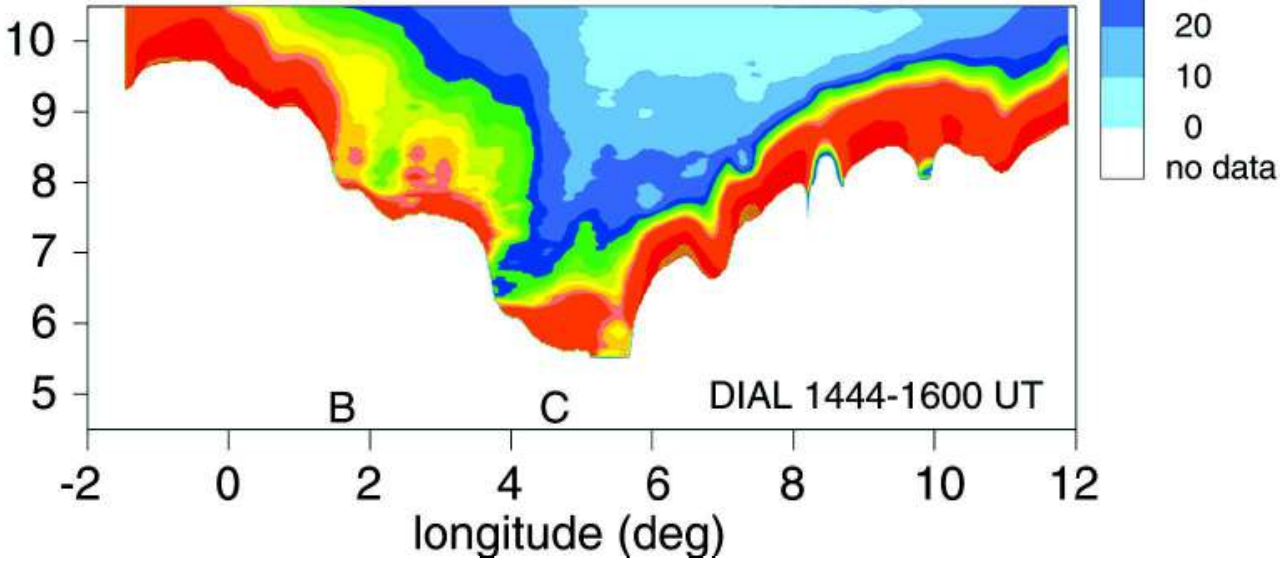

Figure 6. Cross-sections of water-vapour mixing ratio (ppmv) on 6 November 1999 above the baseline given in Fig. 1 (southernmost flight track). (a) Interpolated ECMWF operational analysis from 1515 UTC; (b) data simulated by the mesoscale model Meso-NH from 1515 UTC; (c) data taken by the Differential Absorption Lidar (DIAL) between 1444 and 1600 UTC. The mixing ratio is given in the colour scaling. Note that there is a jump in scaling at the $100 \mathrm{ppmv}$ isoline: the increment being $10 \mathrm{ppmv}$ below and $100 \mathrm{ppmv}$ above. The full lines indicate the potential vorticity (PV), increment $1 \mathrm{PV}$ unit. $\mathrm{B}$ and $\mathrm{C}$ mark the locations of the vertical profiles given in Fig. 4. 
earlier investigation a $10 \mathrm{~Hz}$ DIAL system was used, whereas in the present case lidar data were recorded for the first time at a repetition rate of $100 \mathrm{~Hz}$. Figure 6 shows watervapour mixing ratio (colour) and PV (isolines) data as observed and simulated beneath the southern flight track. The model time, 1515 UTC, coincides with the time when the aircraft passed the centre of the cross-section.

All three datasets show a clear descent of stratospheric air extending towards the west at lower altitudes. This descent, marked by low mixing ratios, occurs down to an altitude of $5 \mathrm{~km}$ at $3^{\circ} \mathrm{E}$, with a similar structure apparent in both the ECMWF and Meso-NH data. In the DIAL data a comparable deep descent cannot be detected because the DIAL wavelength was chosen for maximum resolution and does not enable a penetration through the humid layer sandwiched between the stratosphere and the dry air within the fold region. Further to the east at $5^{\circ} \mathrm{E}$, the DIAL system is able to provide data showing low mixing ratios down to $20 \mathrm{ppmv}$ at an altitude of $6.5 \mathrm{~km}$. A similar feature is observed in the other data, but at higher altitudes. At the western edge of the streamer $\left(2^{\circ} \mathrm{E}\right)$ a second descending tongue of stratospheric air can be seen at $9 \mathrm{~km}$. This secondary tongue appears very clearly in the Meso-NH simulation. The DIAL data also give an indication of this pattern but again, it was not possible to collect sufficient information beneath the more humid layer. Using a Lagrangian backward trajectory technique Liniger and Davies (2003) determined that the air mass within this tropopause descent was advected along an upper-tropospheric track over the three preceding days, being characterized by low humidity values throughout this period. At the eastern edge of the streamer, a series of small-scale tropopause descents and ascents is apparent in the Meso-NH and DIAL data. One weak but clearly noticeable descent of stratospheric air is located at $7^{\circ} \mathrm{E}$. This feature is evident in all the cross-sections. Further to the east, a second descent is located between $7.5^{\circ}$ and $8.0^{\circ}$, apparent only in the Meso-NH and DIAL data. A third descent close to $11^{\circ} \mathrm{E}$ appears in all data.

Furthermore, we note that the three datasets agree fairly well in placing the zonal limits of the streamer (indicated by a threshold value of 70 to $80 \mathrm{ppmv}$ ) at $0^{\circ}$ (western edge at an altitude of $10.5 \mathrm{~km}$ ) and at $12^{\circ} \mathrm{E}$ (eastern edge at an altitude of $9 \mathrm{~km}$ ). Clearly, the Meso-NH data show finer-scale features than the more coarsely resolved ECMWF data. In terms of absolute values for water-vapour mixing ratio, there is reasonably good agreement between all three datasets. The general descent of dry stratospheric air apparent in the mixing-ratio field of the Meso-NH data is similar to the PV field. However, the bridge of increasing mixing ratio between the separated minimum and the main reservoir of dry stratospheric air is not reflected in the PV pattern. An interesting feature appears in the Meso-NH PV data at the eastern rim of the streamer where smallscale maxima and minima occur within the tropopause region.

All three datasets represent a different approach to the real atmosphere. The ECMWF data show a smoothed behaviour based on a grid of approximately $50 \mathrm{~km}$ mesh size. The Meso-NH data portray the real atmospheric state based on a $36 \mathrm{~h}$ simulation on a $8 \mathrm{~km}$ grid. At geographically well defined positions the DIAL system measures vertical backscatter profiles from which the water vapour is calculated using the DIAL equation. In all three systems it is necessary to apply different intermediate steps, such as assimilation schemes (ECMWF), numerical modelling (Meso-NH) and horizontal and vertical averaging (DIAL), in order to finally obtain physical mixing-ratio data. For a quantitative comparison, all those data (Fig. 6) are taken into account for which all three data types were available. Because the location of the DIAL signal is not at the same position as the surrounding ECMWF and Meso-NH data, it was necessary to interpolate the latter two data types to get a value which could be considered to be comparable to the related DIAL data point. 


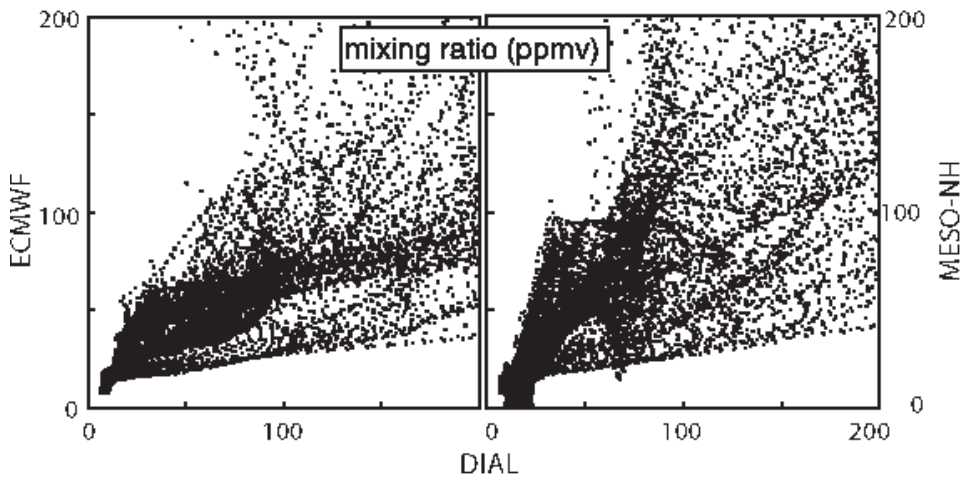

Figure 7. Scatter plots of water-vapour mixing ratio (ppmv) as analysed (ECMWF), simulated (Meso-NH), and measured (Differential Absorption Lidar, DIAL) on 6 November 1999. For related statistics see Table 1.

TABLE 2. CORRELATION AND REGRESSION FOR WATER-VAPOUR MIXING RATIO (6 NOVEMBER 1999)

\begin{tabular}{lcrcccc}
\hline & Range in ppmv & \multicolumn{1}{c}{$\mathrm{N}$} & $\mathrm{C}$ & Error & $\mathrm{R}$ & Error \\
\hline DIAL versus ECMWF & $0-100$ & 10148 & 0.82 & 0.004 & 0.59 & 0.004 \\
& $0-200$ & 12492 & 0.79 & 0.005 & 0.52 & 0.004 \\
& $0-300$ & 13431 & 0.73 & 0.006 & 0.44 & 0.004 \\
DIAL versus Meso-NH & $0-100$ & 9515 & 0.80 & 0.005 & 0.83 & 0.007 \\
& $0-200$ & 12024 & 0.78 & 0.005 & 0.69 & 0.005 \\
& $0-300$ & 13224 & 0.73 & 0.006 & 0.66 & 0.005 \\
\hline
\end{tabular}

$\mathrm{DIAL}=$ Differential Absorption Lidar, $\mathrm{C}=$ correlation coefficient, $\mathrm{R}=$ regression coefficient, $\mathrm{N}=$ sample size.

Figure 7 exhibits a scatter plot showing water-vapour mixing ratios of up to 200 ppmv as analysed (ECMWF), simulated (Meso-NH) and measured (DIAL) on 6 November 1999. For mixing ratios lower than 50 ppmv the scatter is much smaller than for larger mixing ratios. In general there is not a large difference between the structure of ECMWF and Meso-NH data versus DIAL data. This was already the qualitative impression obtained from Fig. 6. A closer examination of the statistical characteristics includes the determination of the correlation and regression coefficients (Table 2). The correlation coefficient as a measure of the quality of the relation between two data series indicates a strong similarity for both comparisons. The error for both coefficients is very small, partly because the data samples are quite large. The type of relation between two parameters is measured by the regression coefficient. Here, the Meso-NH mixing ratios are closer to the DIAL ones than those of the ECMWF and obviously the analysed and simulated humidity are weaker than the measured humidity.

\section{LOWER-STRATOSPHERIC AEROSOL DISTRIBUTION}

It is well known that high aerosol scattering and enhanced ozone mixing ratios are correlated with descending air from the lower stratosphere. In the present case, lidar measurements of aerosols across the streamer are revealed by the backscatterratio distribution beneath the aircraft along $48^{\circ} \mathrm{N}$ (Fig. 8(a)) and $45^{\circ} \mathrm{N}$ (Fig. 8(b)). The measured backscatter ratio within the cloud-free areas ranges from 1.0 to 1.8 . At the eastern flank of the streamer there are mid- to upper-tropospheric clouds which are too thick to be penetrated by the laser beam. Two gaps within the cloud field can be 
(a)

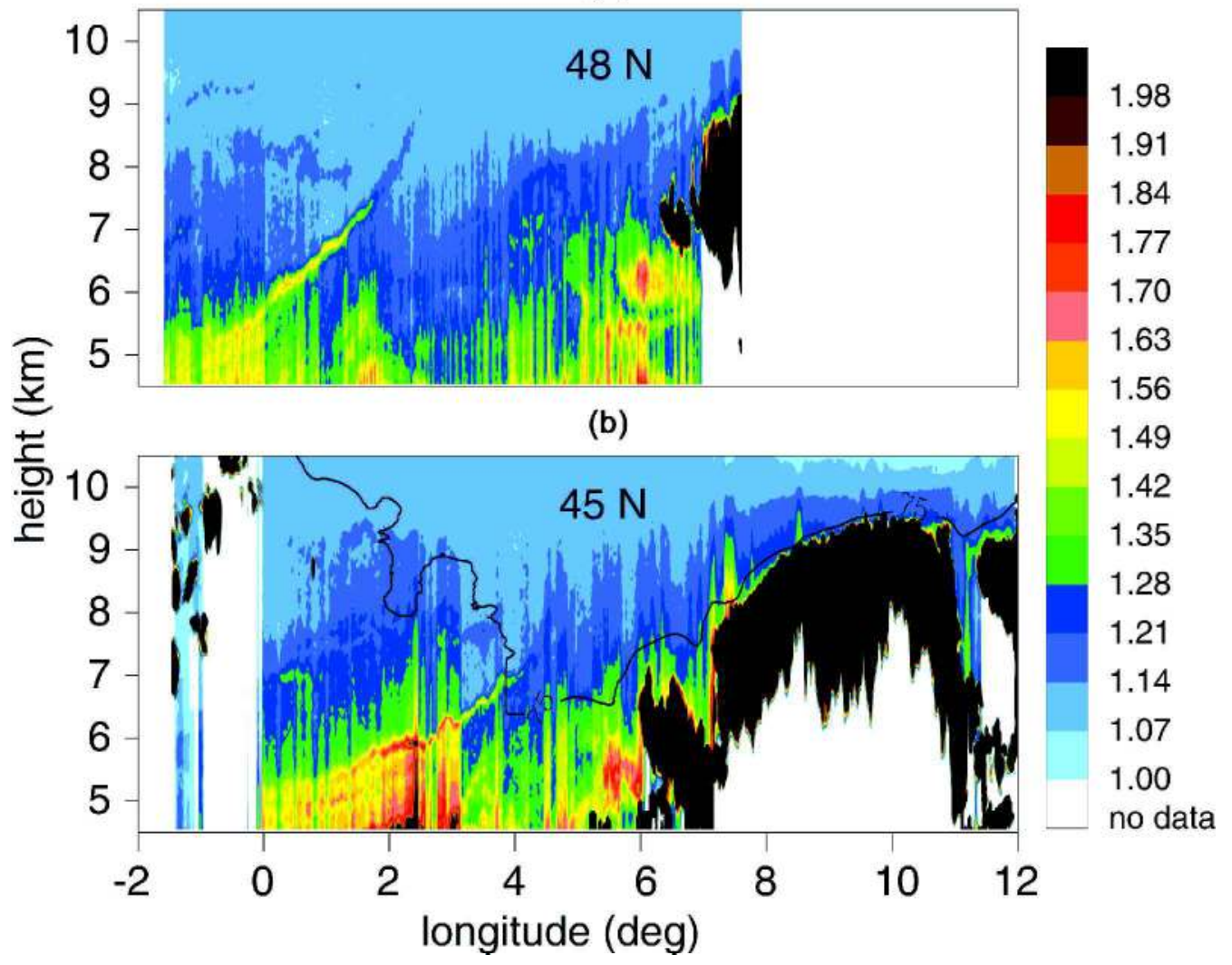

Figure 8. Cross-sections of backscatter ratio along (a) $48^{\circ} \mathrm{N}$ and (b) $45^{\circ} \mathrm{N}$ on 6 November 1999. The black line indicates the $75 \mathrm{ppmv}$ isoline of water-vapour mixing ratio as derived from the Differential Absorption Lidar (DIAL) measurement.

seen at $7^{\circ} \mathrm{E}$ and $11^{\circ} \mathrm{E}$ which coincide with a decrease in mixing ratio compared with the near-zonal environment (Fig. 6).

A coherent pattern appears to the west of the clouds where in both cross-sections there is an extended area of increased backscatter (between $5^{\circ} \mathrm{E}$ and $6^{\circ} \mathrm{E}, 5$ and $6 \mathrm{~km}$ altitude). Another more striking feature can be seen within the western part of both cross-sections where a narrow band of increased backscatter ratio extends eastwards with increasing height. This fine narrow banded structure appears within both crosssections indicating a meridional coherence. The comparison of the structure as seen in the mixing-ratio and backscatter-ratio fields indicates that this narrow band of enhanced backscatter ratio is located at the top of the descending tongue of dry stratospheric air, possibly within the strong gradient region delimiting the tongue's top. As the band is of very fine scale it is not possible to simulate it with the mesoscale model set-up used here.

What mechanisms can produce such a narrow banded structure? There are various possibilities: first, the aerosol-loaded air was produced locally; this does not seem to be probable because the structure is coherent in both sections and as it appears in the form of an elongated narrow band. Second, the aerosol was transported from a surrounding source. One could assume that it was injected from above, from the stratosphere, or 
that the loaded air was transported from a source located within the lower to midtroposphere. In both cases it would be necessary to find some mechanism responsible for transporting air loaded with aerosol into higher or lower levels. Let us assume first that it was transported from below. The vertical-velocity fields as simulated by the Meso$\mathrm{NH}$ do not indicate slantwise vertical transport at the top of the descending tongue of stratospheric air. On the other hand, the lower part of Fig. 8 suggests that the aerosol filament is connected with lower-tropospheric aerosol-loaded air located at $2^{\circ} \mathrm{E}$. If the air originated from the stratosphere an enhancement of the backscatter ratio is plausible by assuming that the dry stratospheric air is brought into a more humid region which would allow the aerosol particles to grow.

Liniger and Davies (2003) support the idea of stratospheric origin by applying a Lagrangian backward trajectory technique. They trace back a moist filament which is located in the same area, to boundary-layer air over the American continent which underwent a strong ascent before approaching Europe. They suggested that the distinctive band aligned with and located above the fold is then formed by zones of high water vapour sandwiched between zones of drier air. This means that relatively humid air enriched with larger particles is located between zones loaded with smaller particles. Unfortunately, there is no DIAL water-vapour data in this altitude region to confirm the humidity structure within and around the striking aerosol filament.

\section{LOWER-STRATOSPHERIC WAVES ABOVE THE Alps}

There are several noteworthy facts supporting the assumption that the streamer got modified above the western Alps. Figures 1 and 2 indicate that the PV field in the tropopause region was distorted above the underlying orography. Figure 3 shows wavetype vertical motion above the Alps, not only above the closer vicinity of the orography but also within the lower stratosphere. During the entire period from November 5 to 8 a strong cross-Alpine surface pressure gradient of about $9 \mathrm{hPa}$ was observed between the northern and southern side of the Alps, which is a necessary prerequisite for föhn in northern Italy and generating mountain waves.

Figure 9 shows the streamer's evolution in the light of the PV anomaly at $320 \mathrm{~K}$ resulting from the Meso-NH simulation. At 12 UTC the complete PV distribution exhibits much more detailed structures than the corresponding ECMWF analysis (Fig. 1). For reasons of clarity, only the contour lines of 3 and 5 PVU are given in the following images, delimiting the grey areas. This area depicts the transition zone between the troposphere with low PV values, and the stratosphere with high PV. In general, it becomes evident that the western and eastern edges of the streamer can be clearly identified by a relatively closed band of 3 to 5 PVU at the beginning of the period. As time progresses the eastern edge becomes diffused, particularly above the Alps.

The structures at the eastern edge and within the inner streamer's vicinity are of relatively small scale, but they show meridionally coherent patterns suggesting waves. The stratosphere is a stable layer in which disturbances transmitted through the tropopause are damped out in general, however, in some circumstances disturbances can be amplified in the stratosphere. The reason for such a wave amplification is the decreased density and wind speed with height, and the lack of absorptive or reflective layers in the upper troposphere and lower stratosphere. The most common mechanism for wave generation is related to cross-mountain flow. These mountain waves are responsible for generating lower-stratospheric clear-air turbulence and, at greater heights, polar stratospheric clouds. Other wave-generating mechanisms are shear instability and convection. 

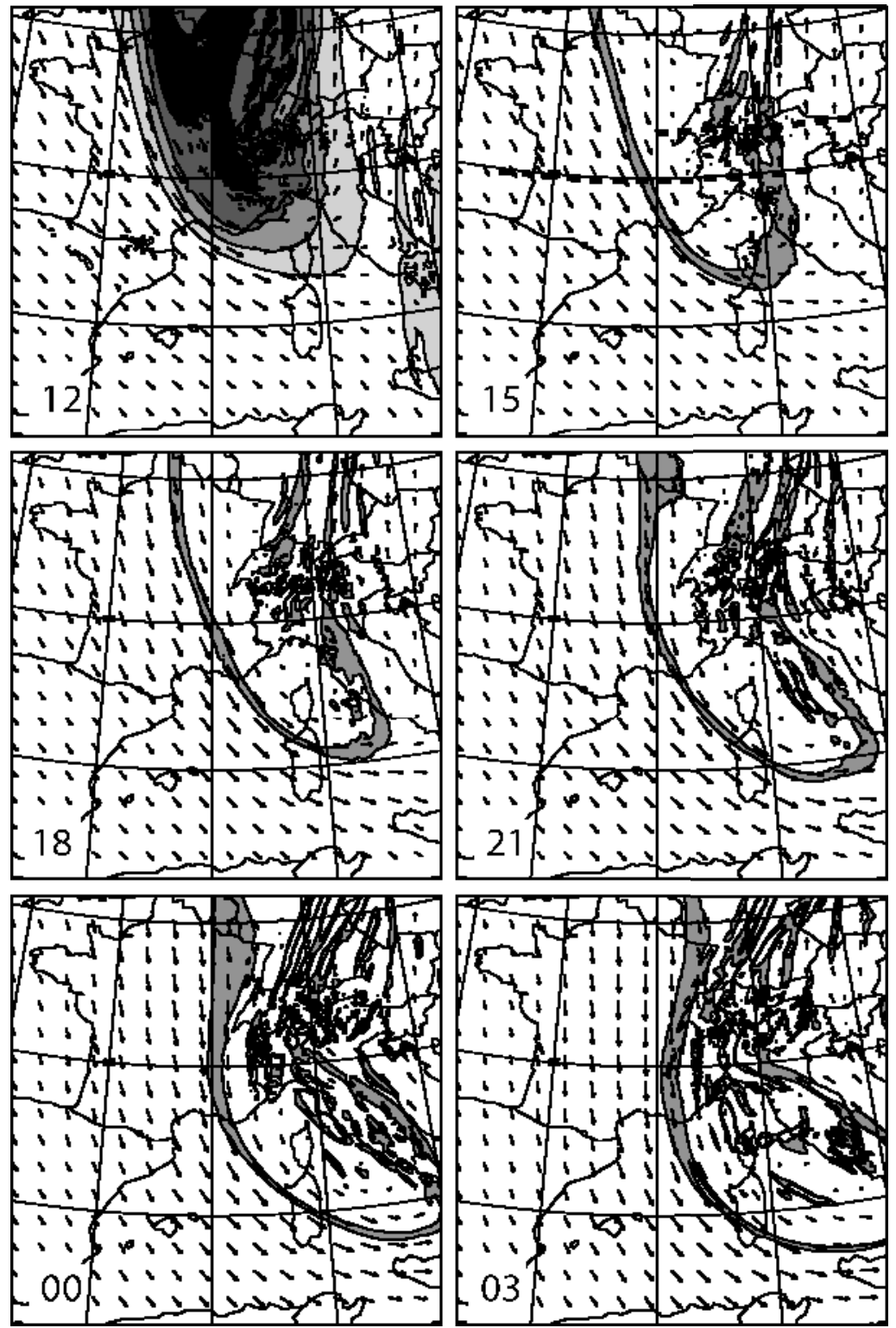

Figure 9. Flow vectors and potential vorticity (PV) at $320 \mathrm{~K}$ between 12 UTC 6 November 1999, and 03 UTC the following day, as simulated by Meso-NH. At 12 UTC the complete PV field is given where the darkness of the shading relates to the magnitude of PV. For the following times only the region between 3 and 5 PV units is marked. The northern dashed line indicates the baseline of the cross-section given in Fig. 10; the southern one shows the southern flight track of the aircraft shown in Fig. 11.

In order to look at the possible generation of mountain waves, the temporal evolution of isentropes within a cross-section which cuts through the centre of action is considered. Its baseline is given in Fig. 9 (15 UTC, northern dashed line). Figure 10 shows the temporal evolution of the isentropes as simulated with the Meso-NH. At 12 UTC, only weak waves can be observed. During the afternoon, waves appear in the layer between 9 and $11 \mathrm{~km}$ which propagate to greater heights with increasing 


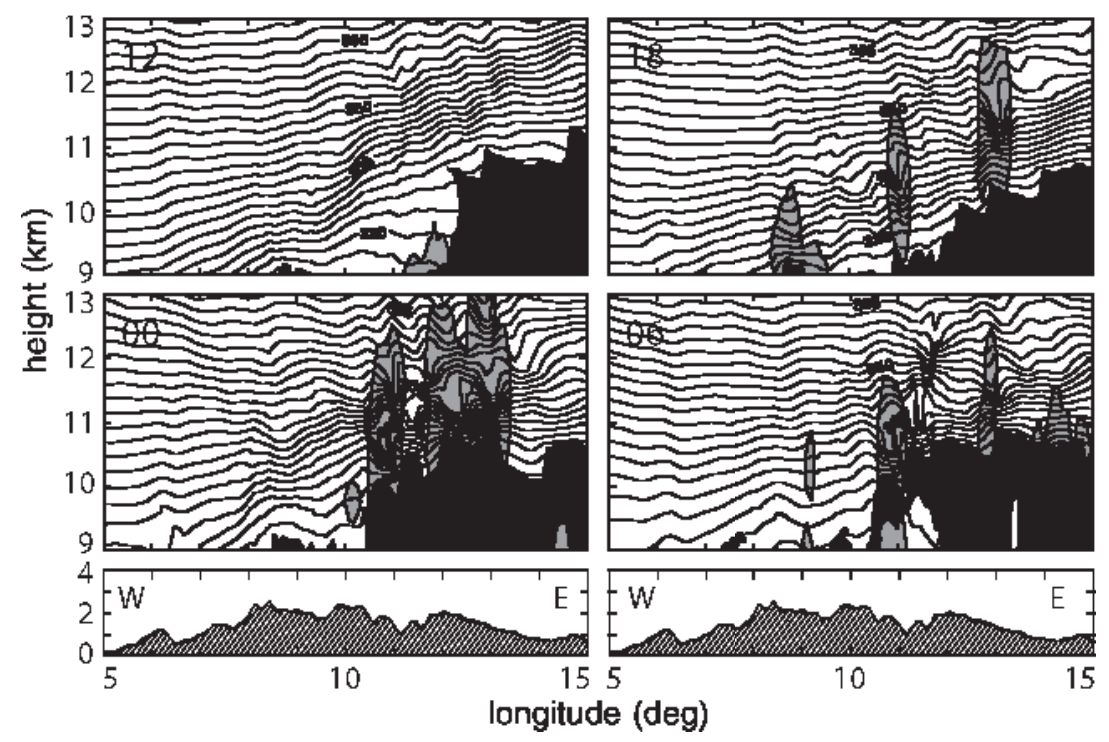

Figure 10. Temporal evolution of isentropes $(\mathrm{K})$ as obtained from a mesoscale simulation between 12 UTC 6 November and 06 UTC 7 November 1999. The baseline is shown in Fig. 9 (15 UTC, northern dashed line). The shaded area indicates production of turbulent kinetic energy. The hatched area marks relative humidity greater than $99 \%$.

amplitude (18 UTC). As soon as the isentropes become vertical and overturn, wave breaking occurs due to convective instability. These waves and the related wave breaking cause turbulent mixing because the vertical transport is irreversible. Shapiro (1980) has shown that turbulent mixing in a tropopause fold is an important process for exchanging chemical constituents and for generating and destroying potential vorticity. Turbulent kinetic energy (TKE) as simulated by the Meso-NH, is produced within the areas of wave breaking (Fig. 10, shaded areas). The peak time of TKE production is around 00 UTC on 7 November.

As soon as the PV streamer approaches the Alps, the vertical gradient in the potential temperature between the orography and the tropopause increases, as can be seen in the layer between 9 and $10 \mathrm{~km}$ in the first two panels of Fig. 10. Changes in the potential-temperature gradient, particularly in its vertical component, lead to an increase in vorticity and a related modification in the potential vorticity as soon as nonconservative processes are acting. The troposphere is disturbed on two scales. There are disturbances on the scale of the entire mountain range and smaller-scale disturbances which are related to mesoscale ridges in the orography and to the field of the isentropes. As a result, eddies in the form of waves are generated in the layer between the orography and the tropopause before they propagate into the stratosphere.

During 6 November 1999 convection and precipitation occurred east of the western Alps above northern Italy. A zone where relative humidity exceeds $99 \%$ is simulated (hatched area in Fig. 10) indicating that the tropospheric air was saturated up to the tropopause. Again the peak hour is around midnight. Figure 6 indicated that waves were apparent in the measured humidity and the simulated PV above the clouds, extending up to the tropopause and suggesting that the convection reaching the upper troposphere generated waves.

Figure 10 shows the result of a numerical simulation, which should be compared with measured data. In situ or remote measurements from the aircraft are not available 


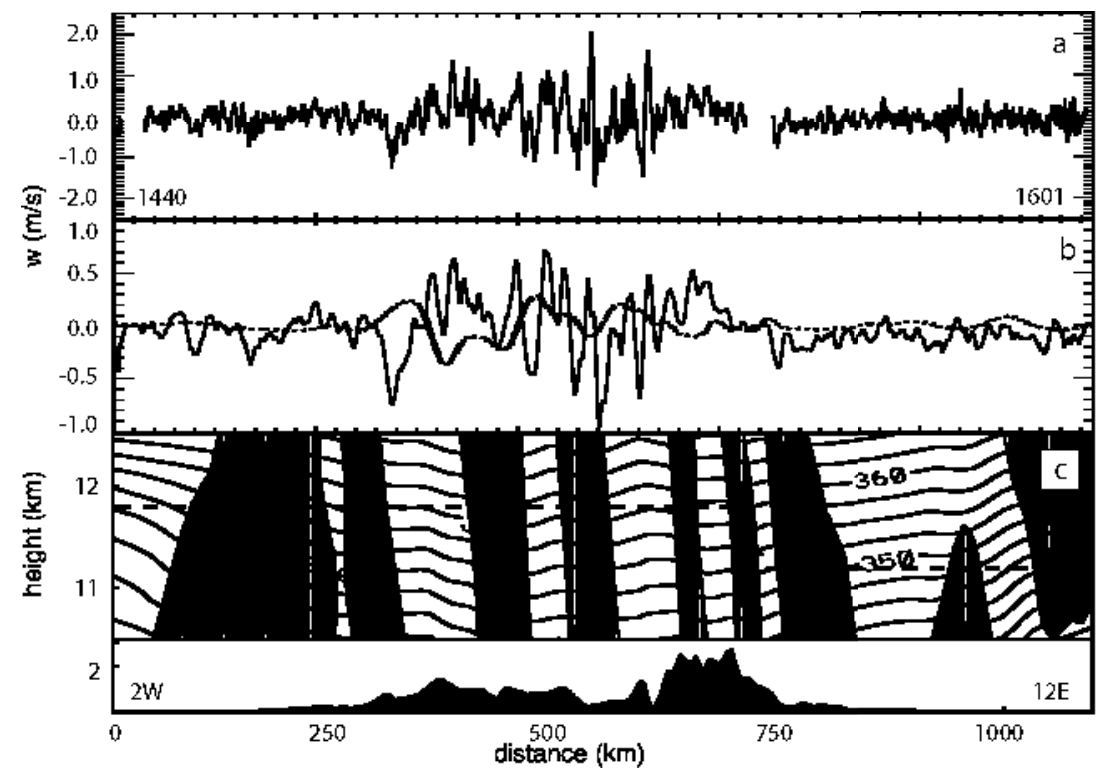

Figure 11. (a) Vertical velocity measured by the aircraft system along the flight track at $45^{\circ} \mathrm{N}$ on 6 November 1999, the time is given in UTC. (b) Flight data after applying a running mean of $50 \mathrm{~s}$ or $10 \mathrm{~km}$ (full line) to the original data (a). The dotted line indicates the simulated vertical velocity. The isentropes between 10 and $13 \mathrm{~km}$ simulated by the Meso-NH at 1515 UTC are given in (c); the shaded areas indicate downward motion. The flight altitude is indicated by the dashed line in (c). The baseline of the track is given in Fig. 9 (see 15 UTC, southernmost dashed line).

from the area of interest. However, along the southern flight track at $45^{\circ} \mathrm{N}$ the aircraft recorded data. Figure 11 shows the vertical velocity measured along the southern flight track and compares it with the numerical simulation (1515 UTC). This reveals that the location of notable wave-generated up- and downdraughts is the same for the observation and the simulation. However, the phase of the measured and simulated waves differs. The amplitudes of the simulated waves are less strong than the observed ones, which is due to the fact that the spatial resolution is very different. Similar evidence is reported by Doyle et al. (2002) and Volkert et al. (2003), who directly compared aircraft observations and mesoscale simulations of Alpine gravity-wave events during the preparation and the execution of the MAP SOP, respectively.

The occurrence of waves in the tropopause region associated with a tropopause distortion is also detected in the wind-profiler data collected above Lonate (Fig. 12). The horizontal wind fields show a convergence zone at an altitude of $10 \mathrm{~km}$. The measurements show a southerly flow throughout the entire troposphere around noon on 6 November, whereas the simulation indicates a south-westerly flow. During the afternoon the low-level flow comes from the north. In the Wipp Valley and at the Brenner Pass the change from south föhn to north föhn associated with the passage of a cold front occurred around 13 UTC, as is shown by the surface pressure data collected along the valley during the MAP SOP (Mobbs and Arnold 2001). The tropopause can be identified by the locations of vertical echo power enhancement (Fig. 12(a), crosses) as well as by the 3.5 PVU contour line (Fig. 12(b), full line). Until 18 UTC the tropopause heights detected by the wind profiler and simulated by the model are in very good agreement, and both data types show an undisturbed tropopause structure. Later on we find more than one power enhancement between 8.5 and $11.5 \mathrm{~km}$ in the wind-profiler data, as well 


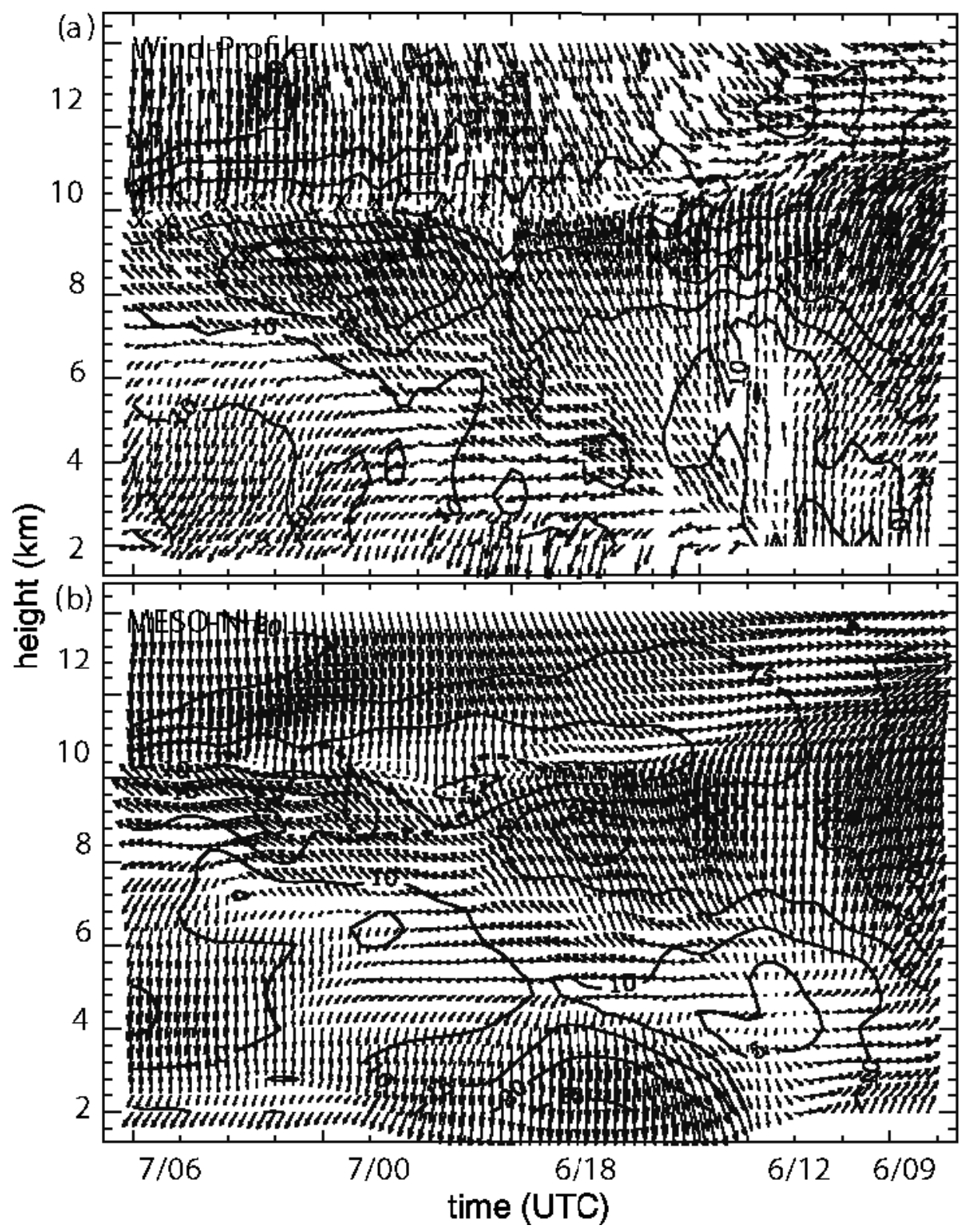

Figure 12. Time-height cross-section of horizontal wind above Lonate taken by a wind profiler (a) and simulated by Meso-NH (b). The crosses in (a) indicate the locations of enhancement in the vertical power echo, the lowermost ones correspond to tropopause heights. The full line in (b) indicates the potential vorticity (PV) tropopause of $3.5 \mathrm{PV}$ units. The full isolines indicate wind speed $\left(\mathrm{m} \mathrm{s}^{-1}\right)$. Time increases from right to left, from 09 UTC 6 November (6/09) to 06 UTC 7 November (7/06). 
as vertical variations of the simulated tropopause within the same layer. At the same time gravity waves were detected by a microbarometric network located in the western Po Valley in the vicinity of Turin (Richiardone et al. 2001).

\section{THE IMPACT OF OROGRAPHY AND DIABATIC PROCESSES}

Morgenstern and Davies (1999) showed that in an idealized flow configuration the orographic effect reduces the PV above the orography somewhat, whereas a disruption of the streamer above the orography results if diabatic effects alone are allowed to occur. In the present case a similar break-off was observed during the occurrence of waves in the tropopause region above the Alps (Figs. 9 and 10). These waves, however, cannot be clearly attributed to their sources, be they mountains or convection. Lower-stratospheric humidity (Fig. 6) and the occurrence of convection (Fig. 8) hint at a convective origin, whereas simulated vertical velocity (Fig. 3), simulated PV and the observed humidity pattern (both Fig. 6) point to mountain waves. In order to distinguish the influence of such waves on the streamer's evolution, four different numerical simulations were performed (see section 2). Following Morgenstern and Davies (1999) the analysis is performed using potential vorticity because the streamer is dynamically characterized by its particular PV signature.

Figure 13 exhibits the streamer's structure at the peak impact time (00 UTC 7 November). Given is the PV, vertically integrated between 500 and $150 \mathrm{hPa}$. Simulation $\mathrm{S}$ reveals that the streamer evolves smoothly in the absence of both orography and diabatic effects. When both effects are included $\left(\mathrm{S}_{\mathrm{TD}}\right)$, the PV structure is broken into small regions of different PV above the Alps and filaments of PV north of this area. This corroborates theoretical results which underline that waves and dissipative processes will lead to a PV flux and generation of regions of positive and negative PV that advect downstream (e.g. Schär and Durran 1997). In simulations $S_{D}$ and $S_{T}$ diabatic and orographic effects are taken into account, respectively. Figure 13 suggests that the fine-scale spotty structure results from the topographic influence, whereas the convection forces filaments above and north of the Alps. It is interesting to note that the spotty structure is clearly related to the eastern and southern slopes of the Alps.

In order to estimate the modification quantitatively, PV is integrated vertically between 7 and $12 \mathrm{~km}$ and horizontally over the Alpine region $\left(5-15^{\circ} \mathrm{E}, 45-48^{\circ} \mathrm{N}\right)$. The averaged PV amounts to: $5.14(\mathrm{~S}), 3.86\left(\mathrm{~S}_{\mathrm{TD}}\right), 4.69\left(\mathrm{~S}_{\mathrm{T}}\right)$, and $4.67\left(\mathrm{~S}_{\mathrm{D}}\right)$. If we consider experiment $\mathrm{S}$ as the reference run, then the combined effects of orography and diabatic processes $\left(\mathrm{S}-\mathrm{S}_{\mathrm{TD}}\right)$ decrease the PV by $25 \%$. The pure orographic effect $\left(\mathrm{S}_{\mathrm{T}}-\mathrm{S}\right)$ reduces the mean PV by $12 \%$, and the pure diabatic effect $\left(\mathrm{S}_{\mathrm{D}}-\mathrm{S}\right)$ by $9 \%$. Thus, the synergetic effect of orography and diabatic effects would reduce the volumeintegrated PV by a further $4 \%$. The main part of the synergetic effect is due to the fact that mountain-generated waves can enhance convection. To test this hypothesis, the topographic and diabatic effects under the related synergetic influences are determined by $\left(S_{\mathrm{TD}}-\mathrm{S}_{\mathrm{D}}\right)$ and $\left(\mathrm{S}_{\mathrm{TD}}-\mathrm{S}_{\mathrm{T}}\right)$, respectively. The synergetic effect due to the presence of orography is calculated as $16 \%$ versus $9 \%$ of the 'pure' diabatic effect. This lends some credence to the hypothesis that convection is increased by orographically forced waves. But there is also a possibility that convection induces mountain waves, at least of moderate strength. As soon as deep convection occurs, the convectionally forced circulation may provide waves in a cross-mountain flow. However, this effect is weak, as is confirmed by the synergetic effect which results in $13 \%$ versus $12 \%$ of the 'pure' topographic effect. All this supports the hypothesis that mountain and/or convectionally 

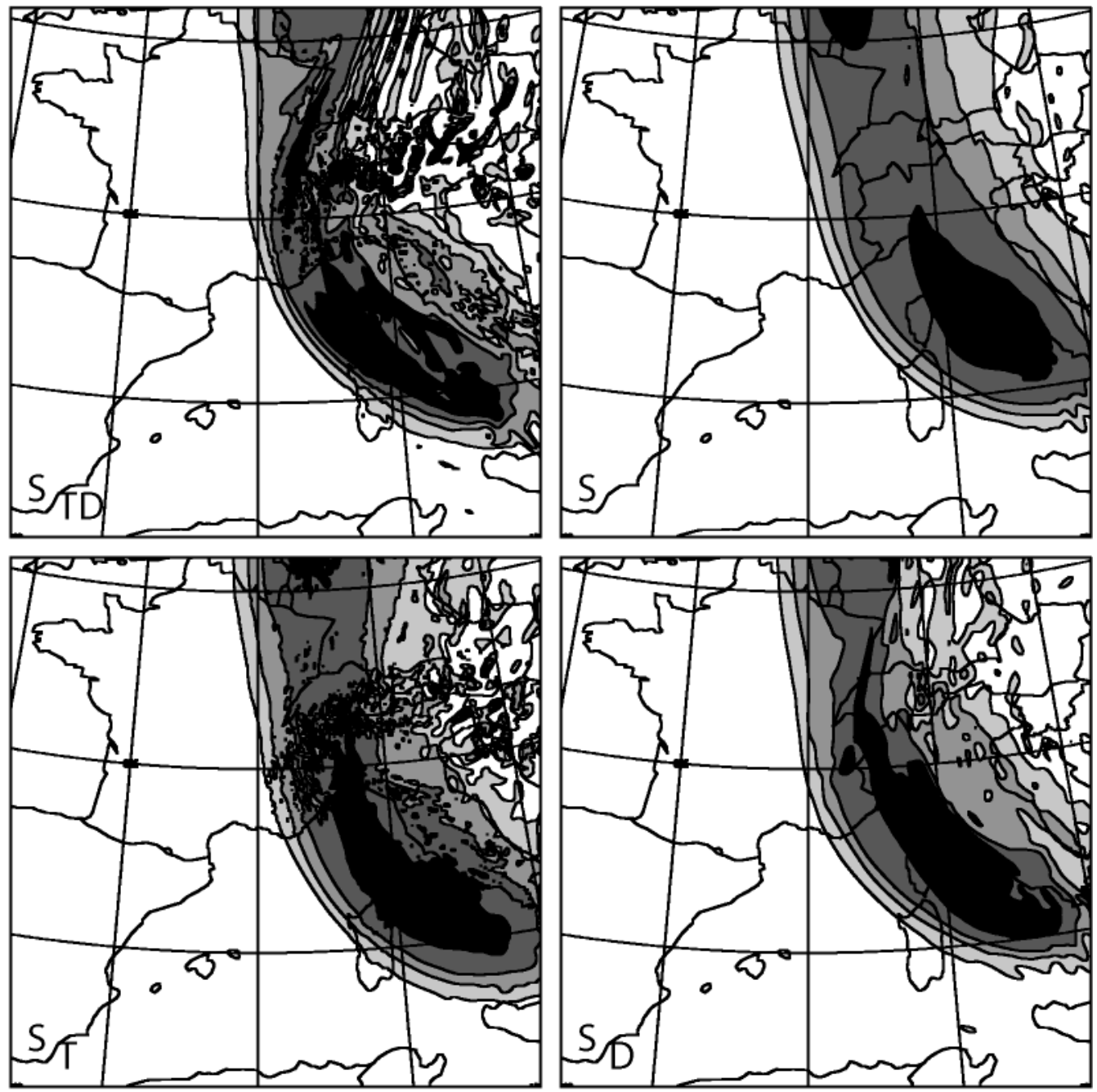

3

4

5

6

\section{potential vorticity (PVU)}

Figure 13 . Vertically integrated $(500-150 \mathrm{hPa})$ potential vorticity at $00 \mathrm{UTC} 7$ November 1999 , for the numerical experiments $\mathrm{S}, \mathrm{S}_{\mathrm{T}}, \mathrm{S}_{\mathrm{D}}$ and $\mathrm{S}_{\mathrm{TD}}$ (see Table 1).

generated waves transmitted into the stratosphere play a role in eroding the streamer's PV.

Figure 14 shows the PV modifications due to the 'pure' diabatic effect, 'pure' topographic effect, the combined effect including their synergetic impact, and the synergetic effect. The diabatic and topographic effects are significant and comparable in magnitude, which was already reported by Morgenstern and Davies (1999). Both effects reduce the streamer's PV, particularly above the Alps. The topographic effect is strong at the streamer's southern end where there is an increase in PV; this points to the evolution of a PV cut-off. The synergetic combination of both diabatic effects and 

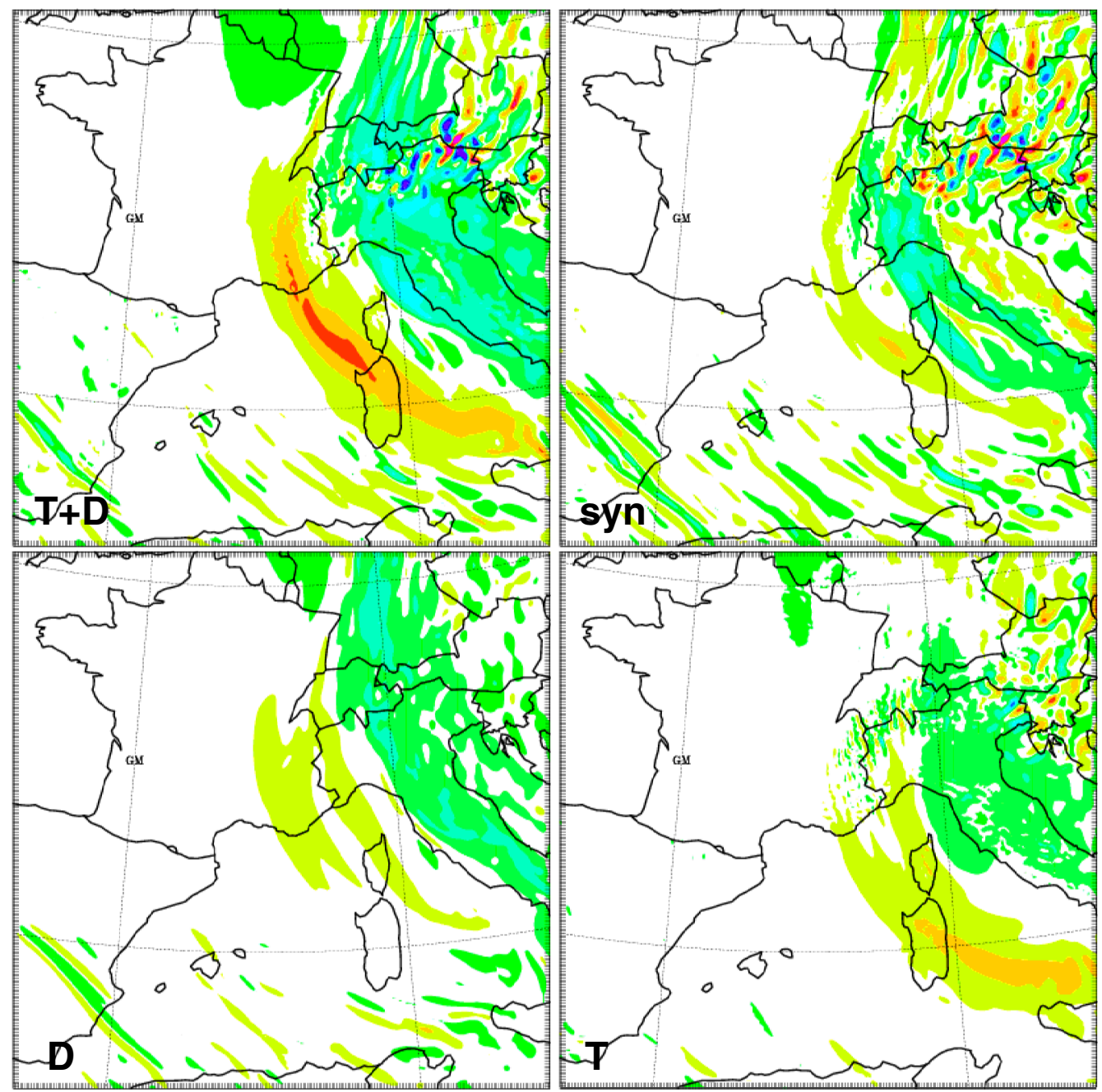

\section{$\begin{array}{llllllllllll}-5.5 & -4.5 & -3.5 & -2.5 & -1.5 & -0.5 & 0.5 & 1.5 & 2.5 & 3.5 & 4.5 & 5.5\end{array}$ potential vorticity (PVU)}

Figure 14. Modification of vertically integrated $(500-150 \mathrm{hPa})$ potential vorticity at 00 UTC 7 November 1999 , due to: the combined effect of topography and diabatic processes $(\mathrm{T}+\mathrm{D})$; pure topography $(\mathrm{T})$; pure diabatic effects (D); and the synergetic effect of $\mathrm{T}$ and $\mathrm{D}$ (syn).

topography shows regions of enhanced negative and positive PV deviations particularly above the central and eastern Alps. Additionally, the PV filaments north of the Alps must be considered as part of the synergetic effect; the source of these filaments appears to be located above the Alps. The combined effect $(\mathrm{T}+\mathrm{D})$ shows an acceleration of the streamer's progression at its southern end. Above the Alps, regions with positive and negative PV deviations appear. At the south-western end of the streamer, the PV is increased which indicates that the orography acts as a pivot supporting the streamer to be wrapped up at its southern end by forming a PV cut-off. 
There is an obvious modification of the upper-tropospheric PV structure which must be related to a corresponding modification in the jet structure. The numerical simulations show that the jet, e.g. at $200 \mathrm{hPa}$, is reduced due to topographic effects above the Alps from 45 to $40 \mathrm{~m} \mathrm{~s}^{-1}$. To the jet's right-hand side this topographic effect is even stronger, e.g. above the Pyrenees, where the jet strength is reduced from 40 to $30 \mathrm{~m} \mathrm{~s}^{-1}$. The impact of diabatic processes weakens the intensity of the jet north of the Alps, whereas the influence on the jet above the orography itself is weak. The total effect of topography and diabatic processes including their synergetic effect results in a reduction of the jet's strength north of and above the Alps. The strong reduction above the Pyrenees is apparent in a narrow band of reduced velocity located directly above the orography.

In addition to the aforementioned topographic and diabatic impacts on the upperlevel structure, there is a possible interaction between an approaching streamer and the orographically bound lower-tropospheric PV generation established by the sustained diabatic heating. The low-level PV generated may induce a modification of the streamer and thereby favour the formation of a PV cut-off. Let us consider a cross-section cutting through the northern Italian region where strong precipitation of up to $55 \mathrm{~mm}$ occurred, in order to estimate the impact of the different effects by calculating the related differences. The combined effect results in a strong upper-tropospheric decrease in PV, and in the lower troposphere a decrease can be seen further to the east above the Julian Alps. The diabatic effect increases the PV in the tropopause region above the Alps and decreases it further to the east. In the lower troposphere PV is generated above northern Italy by diabatic effects which occurred in the region with precipitation. However, in the present case, the generation of low to mid-level PV was generally not very strong beneath the eastern flank of the streamer above northern Italy.

\section{CONCLUDING REMARKS}

The paper presents an integrated analysis of the MAP IOP 15 event of 6/7 November 1999 where a potential-vorticity streamer crossed the Alps. It uses in situ and remotely measured data from an aircraft, mesoscale simulations by the Meso-NH numerical model, wind-profiler data and ECMWF analysis data. It must be emphasized that the data provided by the mesoscale simulations are of key importance for the present analysis because they link all measured data which then provides a consistent picture of the three-dimensional evolution of this event. The major findings of the present study are the following:

- The humidity measured (DIAL) within the streamer and simulated by the models (Meso-NH and ECMWF) shows the characteristic descent of dry stratospheric air with a westward bending of the dry tongue.

- In situ aircraft ozone data indicate that the ozone-rich dry air above the streamer originates from higher stratospheric altitudes.

- Beneath the eastern flank of the streamer there is potential-vorticity generation in those areas where strong updraughts forced precipitation. This potential-vorticity generation, however, reaches altitudes no higher than $5 \mathrm{~km}$. Therefore, in the present case there was no direct interaction between the diabatically generated tropospheric potential vorticity and the streamer's PV.

- Mesoscale numerical simulations and observations indicate the occurrence of waves in the tropopause region above and east of the Alps, beneath the eastern flank of the streamer which propagated into the stratosphere as soon as the streamer approached the Alps. 
- The diabatic and topographic effects are significant and comparable in magnitude. Both effects reduce the streamer's PV, particularly above the Alps. The topographic effect is strong at the streamer's southern end, where there is an increase in PV; this points to the evolution of a PV cut-off. The orography seems to act as a pivot supporting the streamer, to be wrapped up at its southern end by forming a PV cut-off.

- The synergetic effect of topography and diabatic processes shows regions of enhanced negative and positive PV deviations particularly above the central and eastern Alps. North of the Alps the synergetic effect produces PV filaments originating from a source region above the Alps.

Additionally, two more technical aspects were treated successfully. The DIAL operating at $100 \mathrm{~Hz}$, which was employed for the first time during the MAP SOP, demonstrated its capacity to measure low concentrations of water vapour typical of the lower stratosphere with high accuracy and resolution under daytime conditions. The Meso-NH model proved to be able to simulate the main characteristics of the flow features associated with the propagation of a potential-vorticity streamer. This was demonstrated by using wind-profiler data, in situ aircraft data and remotely sensed humidity data.

The main result of the present study lies in the demonstration that orography and diabatic processes play an important role in modifying the streamer's PV structure and in forcing a PV cut-off at its southern end. It is shown that the combined roles of waves generated by mountains and by deep convection, and their impact on the streamer, are of importance for its further evolution. However, it was not possible to distinguish clearly between the impact of mountain waves and convectionally generated waves. This should be investigated in a future study.

Further work will be undertaken for the second strong PV streamer event which was encountered during the MAP SOP (IOP 17). During the MAP SOP it was also planned to perform a thorough validation of the newly developed Differential Absorption Lidar. As the weather was not cooperative during the time when the airborne DIAL was available, a validation mission using in situ aircraft and sonde data was accomplished several months later. Its analysis will also follow as another natural step in the long and complicated process of learning more about the mesoscale details at the tropopause level, using new technology and advanced simulation techniques.

\section{ACKNOWLEDGEMENTS}

We express our gratitude to our colleagues at DLR: Andreas Assion for helping to run the DIAL during MAP, Christoph Kiemle for supporting the processing of the DIAL data, the DLR flight facility for processing the aircraft data, and Hans Volkert for fruitful discussions. Part of this work was performed by the second author (Evelyne Richard) during her one year visit at DLR Oberpfaffenhofen in 2000/2001. The operational ECMWF data were kindly provided by ECMWF within the special project entitled 'The climatology of the global tropopause'. Computer resources for the Meso-NH simulations were provided by IDRIS (Institut du Développement et des Ressources en Informatique Scientifique, Palaiseau, France) under project 569.

\section{REFERENCES}

Appenzeller, C. and Davies, H. C. 1992 Structure of stratospheric intrusions into the troposphere. Nature, 358, $570-572$ 
Appenzeller, C., Davies, H. C. and Norton, W. A.

Bougeault, P., Binder, P., Buzzi, A., Dirks, R., Houze, R.,

Kuettner, J., Smith, R. B., Steinacker, R. and Volkert, $\mathrm{H}$.

Browning, K. A. and Golding, B. W.

Caccia, J.-L., Aubagnac, J.-P., Béthenod, G., Bourdier, C., Bruzzese, E., Campistron, B., Candusso, J.-P., Chérel, G., Claeyman, J.-P., Conrad, J.-L., Cordesses, R., Currier, P., Derrien, S., Despaux, G., Dole, J., Durbe, R.,

Fournet-Fayard, J.,

Frappier, A., Ghio, F.,

Girard-Ardhuin, F.,

Jacoby-Koaly, S., Klaus, V.,

Ney, R., Pagés, J.-P.,

Petitdidier, M., Pointin, Y.,

Richard, E., Seloyan, I.,

Smaïni, L. and Wilson, R.

Doyle, J. D., Volkert, H.,

Dörnbrack, A., Hoinka, K. P. and Hogan, T. F.

Ehret, G., Fix, A., Weiss, V., Poberaj, G. and Baumert, T.

Ehret, G., Hoinka, K. P., Stein, J., Fix, A., Kiemle, C. and Poberaj, G.

Griffiths, M., Thorpe, A. J. and Browning, K. A.

Lafore, J. P., Stein, J., Asencio, N., Bougeault, P., Ducrocq, V., Duron, J., Fisher, C., Héreil, P., Mascart, P., Masson, V.

Pinty, J. P., Redelsperger, J. L., Richard, E. and

Vila-Guerau de Arellano, J.

Liniger, M. A. and Davies, H. C.

London, J. and Oltmans, S. J.

Mobbs, S. and Arnold, S. J.

Morgenstern, O. and Davies, H. C.

Poberaj, G., Fix, A., Assion, A., Wirth, M., Kiemle, C. and Ehret, G.

Richiardone, R., Manfrin, M. and Curiotti, E.

Schär, C. and Durran, D. R.

Shapiro, M. A.

Volkert, H., Keil, C., Kiemle, C., Poberaj, G., Chabourean, J.-P. and Richard, E.
1996 Fragmentation of stratospheric intrusions. J. Geophys. Res., 101, 1435-1456

2001 The MAP special observing period. Bull. Am. Meteorol. Soc., 82, 433-462

1995 Mesoscale aspects of a dry intrusion within a vigorous cyclone. Q. J. R. Meteorol. Soc., 121, 463-493

2001 The French ST-radar network during MAP: Observational and scientific aspects. Meteorologische Zeitschrift, 10, 469-478
1999

2002

1998

1999

2000

1998
Aircraft measurements and numerical simulations of mountain waves over the central Alps: A pre-MAP test case. $Q$. J. $R$. Meteorol. Soc., 128, 2175-2184

Diode-laser-seeded optical parametric oscillator for airborne water vapor DIAL applications in the upper troposphere and lower stratosphere. Appl. Phys. B, 67, 427-431

Low-stratospheric water vapor measured by an airborne DIAL. J. Geophys. Res., 104, 31351-31359

Convective destabilisation by a tropopause fold diagnosed using potential vorticity inversion. Q. J. R. Meteorol. Soc., 126, $125-144$

The Meso-NH atmospheric simulation system. Part I: Adiabatic formulation and control simulations. Annales Geophysica, 16, 90-109

Substructure of a MAP streamer. Q. J. R. Meteorol. Soc., 129, 633-651

The global distribution of long-term total ozone variations during the period 1957-1975. Pure Appl. Geophys., 117, 345-354

'Discontinuous flow evolution along the Wipp Valley during MAP SOP'. Pp. 18-20 in MAP Newsletter No. 15. Meteoswiss, CH-8044, Zurich, Switzerland

Disruption of an upper-level PV-streamer by orography and cloud-diabatic effects. Contrib. Atmos. Phys., 72, 173-186

Airborne all-solid-state DIAL for water vapour measurements in the tropopause region: System description and assessment of accuracy. Appl. Phys. B., 75, 165-172

'Gravity waves detection from microbarometric measurements in the western Po valley'. Pp. 43-46 in MAP Newsletter No. 15. Meteoswiss, CH-8044, Zurich, Switzerland

Vortex formation and vortex shedding in continuously stratified flows past isolated topography. J. Atmos. Sci., 54, 534-554

Turbulent mixing within tropopause folds as a mechanism for the exchange of chemical constituents between the stratosphere and troposphere. J. Atmos. Sci., 37, 994-1004

Gravity waves over the eastern Alps: A synopsis of the 25 October 1999 event (IOP 10) combining in situ and remote-sensing measurements with a high-resolution simulation. $Q$. J.R. Meteorol. Soc., 129, 777-797 